\title{
Studies on Cent Percent Utilization of Recycled Coarse and Fine Aggregates in the Construction Industry
}

\author{
D. Durga Prasad ${ }^{1, *}$, Kishore Ravande $^{2,3}$ \\ ${ }^{1}$ Department of Civil Engineering, University College of Engineering, Osmania University, Hyderabad-500007, Telangana, India \\ ${ }^{2}$ MIT School of Engineering, MIT-ADT University, Pune, Maharashtra, India \\ ${ }^{3}$ Ex Dean Faculty, University College of Engineering, Osmania University, Hyderabad-500007, Telangana, India
}

Received May 9, 2021; Revised August 23, 2021; Accepted September 21, 2021

\begin{abstract}
Cite This Paper in the following Citation Styles
(a): [1] D. Durga Prasad, Kishore Ravande, "Studies on Cent Percent Utilization of Recycled Coarse and Fine Aggregates in the Construction Industry," Civil Engineering and Architecture, Vol. 9, No. 6, pp. 1812-1836, 2021. DOI: 10.13189/сеа.2021.090615.
\end{abstract}

(b): D. Durga Prasad, Kishore Ravande (2021). Studies on Cent Percent Utilization of Recycled Coarse and Fine Aggregates in the Construction Industry. Civil Engineering and Architecture, 9(6), 1812-1836. DOI: 10.13189/cea.2021.090615.

Copyright@2021 by authors, all rights reserved. Authors agree that this article remains permanently open access under the terms of the Creative Commons Attribution License 4.0 International License

\begin{abstract}
As a measure of conserving the resources and for creating eco-friendly environment, studies have been conducted on recycled demolished concrete aggregates (RCA) for their complete usage in the construction industry. The method adopted comprises improving the structure, physical and mechanical properties of RCA. The RCA that are obtained from impact jaw crusher, the surface of these aggregates is improved by processing it through miller machine by way of ball rotation action, where the surface defects and brittle fracture are removed without affecting the permanent mortar adhered on the aggregate, to these modified aggregates which are porous and weak in structure, the surface of the aggregates is subjected to various treatments to improve its structure. The techniques used are densification, hydrophobization, polymerization, and a combination of polymerization \& densification. On these combinations, the various dosages of chemical treatments were applied and tested for their properties on coarse and fine aggregates. Finally, a combination of $2.5 \%$ of Lithium silicate treatment on coarse aggregates and $1 \%$ colloidal silica treatment on fine aggregates has given satisfactory results in usage in concrete/cement mortar mass. On these combinations, the durability and microscopic studies (SEM, EDS, XRD) were done and it was observed that the combination has more association of silica with calcium and these resulted in more formation of $\mathrm{C}-\mathrm{S}-\mathrm{H}$, and a dense interfacial transition zone. The aggregates applicability was tested in the field by using it for various civil works. All the tests and analyzed parameters indicate that the treated aggregates are future materials and act as a complete replacement for natural aggregates.
\end{abstract}

Keywords Strength, Durability, Recycled Aggregates, Treated Aggregates, SEM, EDS, XRD, Concrete, Cement Mortar

\section{Introduction}

\subsection{General}

The whole world is witnessing the depletion of natural resources. Some of the natural resources that are depleting cannot be generated such as natural-made stone and sand, which can neither be created nor be generated. In the name of urbanization, in India, we are exploiting nearly $80 \%$ of these natural resources for our use and left $20 \%$ for the usage of our children. This exploitation already resulted in global warming and catastrophic failures. A 2014 United Nations Environment Programme report, Sand, Rarer Than One Thinks, determined that sand and gravel mining accounts for as much as $\mathbf{8 5}$ percent of all mining activity in the world and concluded that the depletion rate of aggregates is rapidly exceeding its natural renewal rate worldwide. Since, the usage of these natural stones and sand is at the tune of $90 \%$ in concrete production, which in turn is the third maximum consuming material on earth after water and air. Thus, an alternative material usage in places of these aggregates will be boon to the environment and the life of human civilization. In addition to this depletion of Natural Resources, there is an accumulation of waste obtained from these natural resources i.e. construction and demolition (C\&D) materials are generated when new building and civil-engineering 
structures are built and when existing buildings and civil-engineering structures are renovated or demolished (including deconstruction activities). Civil-engineering structures include public works projects, such as streets and highways, bridges, utility plants, piers, and dams. As per the information published by Down-to-earth 513 million tons of debris are generated in India Annually. India needs a landfill which has the same size as West Bengal to dump 21,630 million tons of construction and demolition (C\&D) waste. It will be generated from the repair and demolition of old buildings and new ones between 2005 and 2030. The traditional practice in India is to dispose of this waste in landfills or illegally dump it in rivers and water bodies. Faced with growing environmental concerns and lack of landfill space, as a measure of conserving the resources and for creating eco-friendly environment studies have been conducted on recycled demolished concrete aggregates (RCA) for their complete usage in the construction industry.

\subsection{Objectives of the Work}

The major objectives of the present research work are to conserve and preserve the natural resource by way of reusing the construction demolished waste in form of using it as a complete replacement of natural aggregate i.e. in both coarse and fine aggregate in concrete/mortar mass. The following are the main objectives to achieve the major goal.

- To evaluate the surface modification methods that can produce a refined version of processed recycled demolished concrete aggregate which will be free from the brittle defects without damaging the adhered cement mortar surface on the aggregate mass.

- To arrive at the best surface treatment methodology on coarse and fine recycled demolished concrete aggregates.

- To obtain a combination of treatment methodology on recycled coarse and fine aggregate that can be used ascent percentage replacement of natural aggregates in cement mortar and concrete.

- To assess the performance of concrete made completely out of treated coarse and fine aggregates under severe exposure conditions (Durability study).

- To study the impact of treatment technique on the concrete/mortar mass by analyzing the internal structure and finding the chemical composition and its influence on surface morphology. A complete in detail internal macro and microanalysis and its impact on the properties modification.

- To study the interfacial transition zone on the concrete samples made of treated and untreated aggregates.

- $\quad$ To arrive at the least skilled-based surface modification methods and the best cost-benefit treatment technique that can yield in the production of the strong and durable concrete mass.

- $\quad$ To study field acceptance criteria by using the treated recycled demolished concrete aggregates physically in the field for various field applications.
In the later part of the research, the laid objectives prove to be effective in achieving the desired goal, and also the process defined in the objectives has given the desired results.

\subsection{Literature Review}

Since the main focus of the research work is on the possibility of using large quantities of construction and demolition waste generated as a result of the demolishing either through manmade or through the nature of concrete structures as an aggregate in concrete.

Earlier Various research has been conducted to investigate the possibility of either coarse or fine aggregate as a partial replacement to conventional aggregates in concrete and cement mortar, but due to weak physical properties of the recycled aggregates, its usage was limited, and recently some researchers developed surface improvement methods for improving the recycled aggregate properties, Among that research works, the research was done by Amnon Katz[2] on treatment methods to be adopted for the improvement of recycled aggregate; where the microstructure of recycled aggregate prepared from the crushing of old concrete was studied. It was found that the recycled aggregate is covered with loose particles that may prevent good bonding between the new cement matrix and the recycled aggregate. The old cement paste that remained on the natural aggregate was porous and cracked, leading to weak mechanical properties of the recycled aggregate. Treatment of the recycled aggregate by impregnation of silica fume solution and by ultrasonic cleaning was studied to overcome the above-mentioned limitations. An increase of $~ 30$ and $~ 15 \%$ in the compressive strength at ages 7 and 28 days was observed after the silica fume treatment. Ultrasonic treatment led to an improvement of $\sim 7 \%$. The impregnation technique is used as a surface treatment method for the present research work.

A study by Hwa-Sung Ryu [6] on "Evaluation on the Surface Modification of Recycled aggregate in aqueous H2SiF6 solution", since recycled aggregates bring about a decrease in several performances when they are used for recycled aggregate concrete (RAC) because of the low qualities caused by the attached hydrated cement paste on the RA surface. The physical properties and mechanical performance of mortars using RFA were evaluated after RFA modification. Consequently, the proposed method undertaken by researchers was effective in reducing the water absorption rate and increasing the density of RFA. The treatment resulted in acidic mass, and it was employed on the fraction of fine aggregates. The treatment technique and its adopted method are important points to be noted.

Vivan W Y Tam [7] did experimental work on the microstructural analysis of recycled aggregate concrete produced from a two-stage mixing approach. under these, the paper aims at examining the current practices in the application of recycled aggregate concrete (RAC) and the 
two-stage mixing approach (TSMA) was proposed to improve the quality of RAC. Experimenting with the TSMA and assessing the benefits possibly gained and conducting the microstructural analysis to explore the mechanism of TSMA, the process adopted resulted in an improvement in the strength of recycled aggregate concrete. The negative effects have been attributed to the porous nature of the recycled aggregate concrete and hence the premix process can fill up some pores and cracks, resulting in a denser concrete, an improved interfacial zone around recycled aggregate, and thus strength is higher compared with the traditional mixing approach. The paper findings help in knowing the microstructural improvement techniques in improving the properties of the aggregates. Hasib Yaprak [8] did a detailed study on the effect of the fine recycled concrete aggregate on the concrete properties, in this experimental study, the effect of the recycled fine concrete aggregates (FRA) that was manufactured from the concrete tastes on the concrete properties were investigated. In concrete mixtures 0,10 , $20,30,40,50$, and $100 \%$ by weight FRA were used instead of river sand. Afterward, unit weight and water absorption ratios and 28-days compressive strength were determined accordingly to the test results obtained. It was seen that FRA can be used up to $10 \%$ ratio for producing C30 concrete, and between $20-50 \%$ ratios for producing C25 Concrete.

A review of past studies indicates that there were no studies on complete usage of combined recycled coarse and fine aggregates in the concrete /mortar making process and further limited studies were on the surface modification and its improvement mechanism on recycled coarse and fine aggregates. The paper aims at identifying the route cause that preventing the usage of recycled coarse and fine aggregate in concrete and addressing those route cause issues and developing the surface modification and improvement technique, analyzing its effects and in-depth study on the chemical components and its formation analysis.

\section{Surface Modification and Treatment Techniques}

From the literature review, it can be inferred that the hydrated cement particles on the aggregate surface are of porous nature and have high water absorption properties and the hydrate cement surface on aggregate is a combination of calcium silicate hydrate(C-S-H) and Calcium Hydrate $(\mathrm{Ca}(\mathrm{OH}) 2)$ Chemical. To control porosity and arrest water absorption properties, the formation of $\mathrm{Ca}(\mathrm{OH}) 2$ should be controlled. To control these, the chemistry of Cement Hydration plays a vital role. As cement hydrates, it produces calcium silicate hydrate(C-S-H). As the concrete hardens, water reacts with cement to form calcium hydroxide and silica, which reacts to form C-S-H, and these material bonds the cement with the aggregate in concrete. But the hydration process produces more calcium hydroxide than is used up in this chemical reaction, resulting in excess calcium hydroxide also called free lime. Over the long term, excess free lime is troublesome because it is the primary cause of micron pitting. This excess calcium hydroxide along with hardened C-S-H constitutes the main parts of hydrate cement particles. Our research emphasis is put on how well this excess lime present in concrete demolished will be used for closing the pores and also for densifying the recycled aggregate particles and the recycled aggregate is put to use. Further, the adhered mortar has a weak interfacial transition zone between the original aggregate and cement mortar adhered to its surface, these weak interfacial zones are removed through the ball milling mechanisms, i.e., the obtained aggregates are rotated in ball miller during rotation of miller with the metal ball in the miller and this will impart friction between the aggregates and removes all weak interfacial zones and if any surface defects are also removed. Through these processes, surface defects are removed, and it also imparts surface smoothness to aggregate, the above technique is more effective on a coarse aggregate and on fine aggregate as absorbed through industrial microscopic the effect is limited to $2.36 \mathrm{~mm}$ size aggregate, beyond which the surface modification by ball mill method is not effective. After the surface modification, surface treatment techniques are applied to these aggregates which mainly comprises of initiation of rehydration process in the form of densification, the other method is the creation of hydrophobic surface on the surface of the aggregates through Hydrophobization, the third technique is the usage of polymer on the aggregate surface and the last one is the combination of both densification and polymerization, the details of each treatment technique along with its chemical reaction with the aggregate has dealt below, the surface treatment techniques are applied both on demolished concrete i.e. on a coarse aggregate and fine aggregate, which are as follows

A. DENSIFICATION OF AGGREGATE: In this technique, the rehydration process is initiated by the initiation of C-S-H formation by adding silica in liquid form to recycled demolished concrete aggregate. The intruding of additional silica into the surface/pores of recycled demolished concrete aggregates will react with the excess calcium hydroxide to form more C-S-H. Additional C-S-H means the denser and harder aggregate. Because the aggregate on which cement particles are there is already dry, this additional chemical reaction initiate by liquid chemical hardener/densifiers takes place in the capillaries left by water that migrated out of these recycled demolished concrete aggregates during the curing process. This filling of the capillaries during the densification process provides an additional degree of impermeability and denser mass. Based on this concept, silica-rich chemicals such as sodium silicate, lithium silicate, and Colloidal silica dioxide have been used in the initiation of the rehydration process in recycled demolished concrete aggregate. In terms of a chemical reaction, the above process is as below; 


\section{For Tricalcium Silicate}

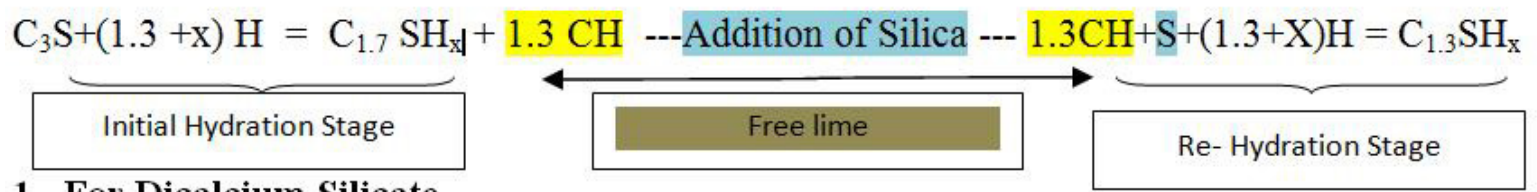

\section{For Dicalcium Silicate}

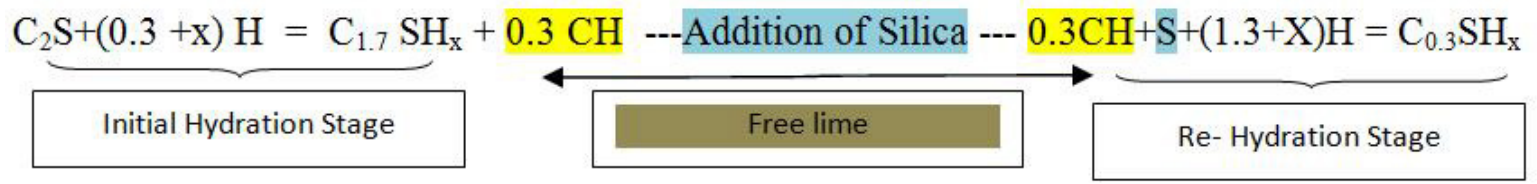

B. HYDROPHOBIZATION OF AGGREGATES: The concrete demolished recycled aggregates, both coarse and fine aggregate, have high water absorption which is mainly due to adhered mortar and carbonization of aggregates. The adhered mortar which was partly carbonated consists of calcium ions. These excess calcium ions will be used for the creation of impermeable surface. For this purpose, one of the best compounds which can impart impermeability by reacting with excess lime and $\mathrm{CaCO}_{3}$ is stearic acid which is a fatty acid with chemical formula as $\mathrm{CH} 3(\mathrm{CH} 2) 16 \mathrm{COO}-$. These fatty acids upon hydrolysis with recycled demolished concrete aggregates react with the free calcium ions i.e. the $\mathrm{Ca}_{2}+$ reacts with $\mathrm{CH} 3(\mathrm{CH} 2) 16 \mathrm{COO}-$ to form hydrophobic $\mathrm{Ca} \quad\left(\mathrm{CH}_{3} \quad(\mathrm{CH} 2) \quad 16 \quad \mathrm{COO}\right)_{2}$, and thus formed $\mathrm{Ca}\left(\mathrm{CH}_{3}\left(\mathrm{CH}_{2}\right) 16 \mathrm{COO}\right)_{2}$ which are deposited on the $\mathrm{CaCO}_{3}$ precipitate formed during the carbonation of $\mathrm{Ca}(\mathrm{OH})_{2}$. Thus, the alkaline chain of stearic acid makes the Caco3 hydrophobic and it also imparts impermeable surface on the top of recycled demolished concrete aggregates.

The chemical equation can be explained as below.

$$
\begin{aligned}
\mathrm{Ca}(\mathrm{OH})_{2}+\mathrm{CO}_{2} & =\mathrm{CaCO}_{3}+\mathrm{H}_{2} \mathrm{O} \\
\mathrm{Ca}^{2+}+2 \mathrm{CH}_{3}\left(\mathrm{CH}_{2}\right)_{16} \mathrm{Coo}^{-} & \left.=\mathrm{Ca}\left(\mathrm{CH}_{3}\left(\mathrm{CH}_{2}\right)_{16}\right) \mathrm{Coo}\right)_{2}
\end{aligned}
$$

C. POLYMERISIATION OF AGGREGATE: In this method of treatment, the recycled aggregate internal pores and weak interfacial transition zone areas are treated. The above treatment methodology is similar to Hydrophobization but here the chemical is penetrated into aggregates pores and through a chemical reaction internal impermeability is created which is done through silane siloxane. These silanes and siloxane have smaller molecular sizes, which allow them to reach smaller pores, resulting in more effective surface treatments. Silane compounds are based on the silane structure. In general structure of silane derivatives, where $\mathrm{R}$ represents an alkyl, aryl, or other organs functional group and OR' generally represents an alkoxy functional group. The silane siloxane of interest has alkoxy groups that can chemically bond to hydrated silicates, leaving a concrete surface modified with hydrophobic alkyl groups. In addition to their hydrophobic effect, these substances impart a strong impermeable surface and also impregnation of this chemical in aggregate pores increase its weight and helps in improving the physical properties of the aggregates.

D. COMBINATION OF DENSIFICATION \& POLYM-ERIZATION OF AGGREGATE: In this methodology, a combination of densification and polymerization is used, where both initiation of rehydration and hydrophobic properties were induced on the surface of the aggregate. As gathered, a combination of Kaolin and Polyvinyl alcohol (PVOH) has the above-described properties. The densification chemicals kaolin which is heavier than water and having an anti-caking agent gets fixed easily with a polymeric solution of polyvinyl alcohol. It was found that the rate of water evaporation depends on the hydrophilic character of the latex polymer. Therefore, a powder containing $\mathrm{PVOH}$ and kaolin which both contain hydrophilic hydroxyl groups exhibit which helps with effective rehydration of recycled aggregate properties. Kaolin is an ore that can be found in nature, and its predominant mineral is kaolinite (higher amount to 90\%). This mineral belongs to the aluminosilicate group.

$$
\begin{gathered}
\mathrm{Al}_{2} \mathrm{O}_{3} \cdot 2 \mathrm{SiO}_{2} \cdot 2 \mathrm{H}_{2} \mathrm{O} \rightarrow \mathrm{Al}_{2} \mathrm{O}_{3} \cdot 2 \mathrm{SiO}_{2}+2 \mathrm{H}_{2} \mathrm{O}+\mathrm{CaOH} \rightarrow \mathrm{Ca}_{2} \mathrm{Al}_{2} \mathrm{Si}_{3} \\
0,(\mathrm{OH})_{2}
\end{gathered}
$$

Interestingly, kaolin appears to accelerate the silicate reaction. And these concept is used in the Recycled concrete aggregate densification and polymerization, whereas the kaolin reacts with lime and accelerates the silicate reaction, where the hydroxyl group of $\mathrm{PVOH}$ forms a hydrated bond with the basal surface of Kaolin in consideration, And the water-soluble polymer which is used to migrate into the interface and has the hydrophobic property and the hydrophobic is the backbone of $\mathrm{PVOH}$ is oriented to the hydrophobic air, whereas its hydroxyl groups interact with the aqueous phase and thus stabilizes the water and /air interface.

\section{Research Methodology}

Details of the methods to be adopted in preparing the test specimens and the different test procedures to be conducted are discussed. The research methodology program consisted 
of ten main stages, the layout of which is shown in the figure 1 .

\begin{tabular}{|c|c|}
\hline Stage 1 & $\begin{array}{l}\text { Selecting aggregates both natural and recycled concrete } \\
\text { aggregates } \\
\text { Evaluating aggregate properties } \\
\text { Selecting suitable chemicals for chemical treatment on } \\
\text { recycled concrete aggregates. }\end{array}$ \\
\hline Stage 2 & $\begin{array}{l}\text { Removing the Surface Defects on recycled concrete } \\
\text { aggregates } \\
\text { Ball Mill Method processing on recycled demolished } \\
\text { concrete aggregate(both fine and coarse aggregates) }\end{array}$ \\
\hline Stage 3 & $\begin{array}{l}\text { Surface Treatment on Coarse and Fine aggregates } \\
\text { Evaluating physical properties on treated recycled } \\
\text { demolished concrete aggregates. }\end{array}$ \\
\hline Stage 4 & $\begin{array}{l}\text { Evaluating the best combination of surface treatment on } \\
\text { recycled demolished concrete fine Aggregates } \\
\text { Byways of conducting compressive strength on Mortar } \\
\text { Cubes }\end{array}$ \\
\hline Stage 5 & $\begin{array}{l}\text { Graphical analysis of coarse aggregate properties with } \\
\text { reference to conventional aggregates } \\
\text { Deciding on the best treatment methodology to be } \\
\text { adopted on Coarse aggregate. }\end{array}$ \\
\hline Stage 6 & $\begin{array}{l}\text { Mix design is based on the properties of aggregates } \\
\text { obtained through different treatment techniques. } \\
\text { Evaluating compressive strength for deciding the best } \\
\text { combination technique to be employed. }\end{array}$ \\
\hline Stage 7 & $\begin{array}{l}\text { Evaluating mechanical properties on concrete based on } \\
\text { the obtained best combination. of treatment, the } \\
\text { technique to be used on aggregates. }\end{array}$ \\
\hline Stage 8 & $\begin{array}{l}\text { Durability studies on the concrete specimen as prepared } \\
\text { in Stage } 7 \text { are evaluated to access its susceptibility to } \\
\text { extreme conditions of exposures and its internal water } \\
\text { absorption and the water flow through the internal voids } \\
\text { will be evaluated. }\end{array}$ \\
\hline Stage 9 & $\begin{array}{l}\text { Microscopic analysis in the form of XRD, EDS, and } \\
\text { scanning electron microscope to study the internal } \\
\text { structure and chemical chemistry. }\end{array}$ \\
\hline $\begin{array}{c}\text { Stage } \\
10\end{array}$ & ( \\
\hline
\end{tabular}

\section{Experimental Work}

As defined in the Research Methodology, the recycled demolished concrete coarse and fine aggregate is treated with various chemicals. On the treated and the untreated recycled demolished concrete coarse and fine aggregates, the physical properties are evaluated along with that of natural coarse and fine aggregates. The results of the same are graphically represented at Figure 1,2,3,4. (NCA-Natural Coarse Aggregates, RCA-Recycled Coarse Aggregates, NA-Sodium Silicate, LI-Lithium Silicate, SI-Colloidal Silica, ST-Stearic Acid, SS-Silane Siloxane, PK-Polyvinyl Kaolin)(NF-Natural Fine Aggregate, MS-Manufacture Sand, RF/RFA-Recycled fine aggregate). The testing is as per the procedure defined in Indian Standard Codes [1], [3], [7]. The properties of the material used are shown as below i.e for cement at Table 1, 2; For Different types of Coarse and Fine Aggregates at Figure $1,2,3,4$.

Table 1. Physical Properties of Cement

\begin{tabular}{|c|c|c|}
\hline $\begin{array}{c}\text { Sl } \\
\text { No }\end{array}$ & $\begin{array}{c}\text { PROPERTIES OF } \\
\text { CEMENT TESTED }\end{array}$ & TEST RESULTS \\
\hline 1. & Type of Cement & $\begin{array}{c}\text { Ordinary Portland } \\
\text { Cement }\end{array}$ \\
\hline 2. & Grade of Cement & 53 \\
\hline 3. & Specific Gravity & 3.14 \\
\hline 4. & Bulk Density(kg/liter $\left.{ }^{3}\right)$ & 1500 \\
\hline 5. & Normal Consistency (\%) & 26 \\
\hline 6. & Fineness (\%) & 4.5 \\
\hline
\end{tabular}

Table 2. Chemical Composition of Cement

\begin{tabular}{|c|c|c|}
\hline $\begin{array}{c}\text { SI } \\
\text { No }\end{array}$ & $\begin{array}{c}\text { CHEMICAL } \\
\text { CONSTITUESTS }\end{array}$ & TEST RESULTS \\
\hline 1 & $\mathrm{Cao}$ & 66.67 \\
\hline 2 & $\mathrm{SiO}_{2}$ & 18.91 \\
\hline 3 & $\mathrm{Fe}_{2} \mathrm{O}_{3}$ & 4.94 \\
\hline 4 & $\mathrm{Al}_{2} \mathrm{O}_{3}$ & 4.51 \\
\hline 5 & $\mathrm{SO}_{3}$ & 2.5 \\
\hline 6 & $\mathrm{MgO}$ & 0.87 \\
\hline 7 & $\mathrm{~K}_{2} \mathrm{O}_{3}$ & 0.43 \\
\hline 8 & $\mathrm{Na}_{2} \mathrm{O}$ & 0.12 \\
\hline 9 & Loss on Ignition & 1.05 \\
\hline
\end{tabular}




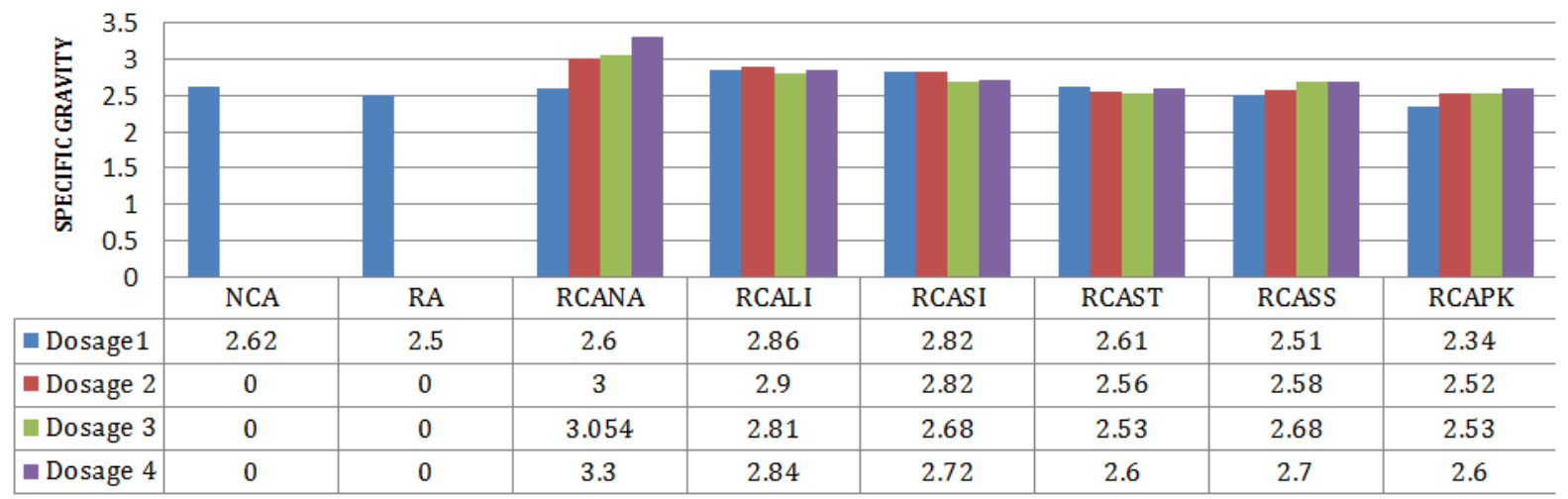

Figure 1. Specific Gravity Values of Treated and Untreated Coarse Aggregates

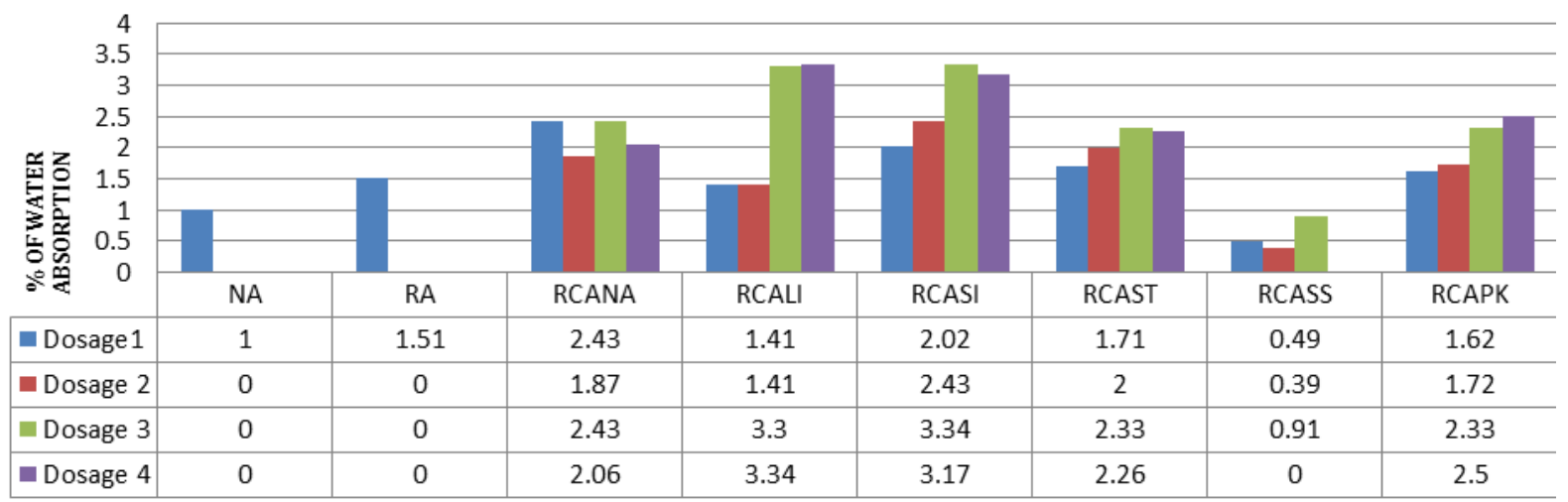

Figure 2. Water Absorption Values of Treated and Untreated Coarse Aggregates

\begin{tabular}{|c|c|c|c|c|c|c|c|c|c|}
\hline 2.5 & & & & & & & & & \\
\hline 2 & & & & & & & & & \\
\hline 1.5 & & & & & & & & & \\
\hline 1 & & & & & & & & & \\
\hline 0.5 & & & & & - & & & & \\
\hline 0 & & & & & & & & & \\
\hline & NA & MS & RA & RFANA & RFALI & RFASI & RFAST & RFASS & RFAPK \\
\hline Dosage1 & 2.56 & 2.578 & 2.117 & 2.51 & 2.46 & 2.54 & 2.43 & 2.2 & 2.266 \\
\hline Dosage 2 & 0 & 0 & 0 & 2.4 & 2.43 & 2.56 & 2.07 & 1.817 & 2.266 \\
\hline Dosage 3 & 0 & 0 & 0 & 2.39 & 2.43 & 2.58 & 2.04 & 1.78 & 2.276 \\
\hline Dosage 4 & 0 & 0 & 0 & 2.3 & 2.4 & 2.35 & 2.06 & 1.75 & 2.2 \\
\hline
\end{tabular}

Figure 3. Specific Gravity Values of Treated and Untreated Fine Aggregates

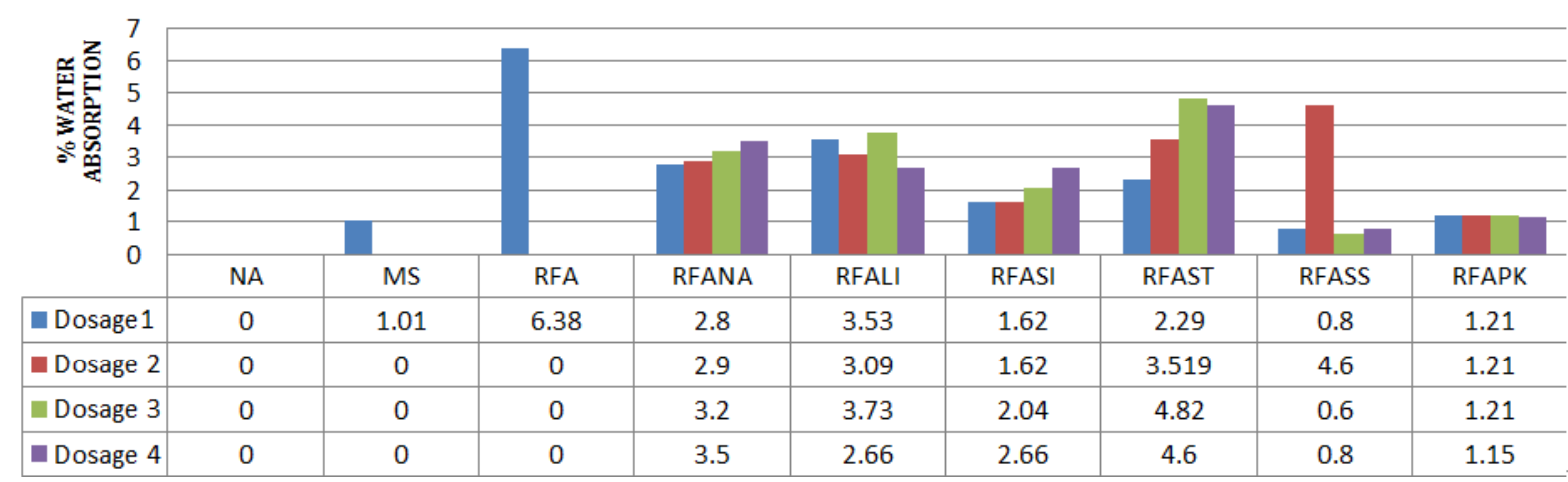

Figure 4. Water Absorption Values of Treated and Untreated Fine Aggregates 


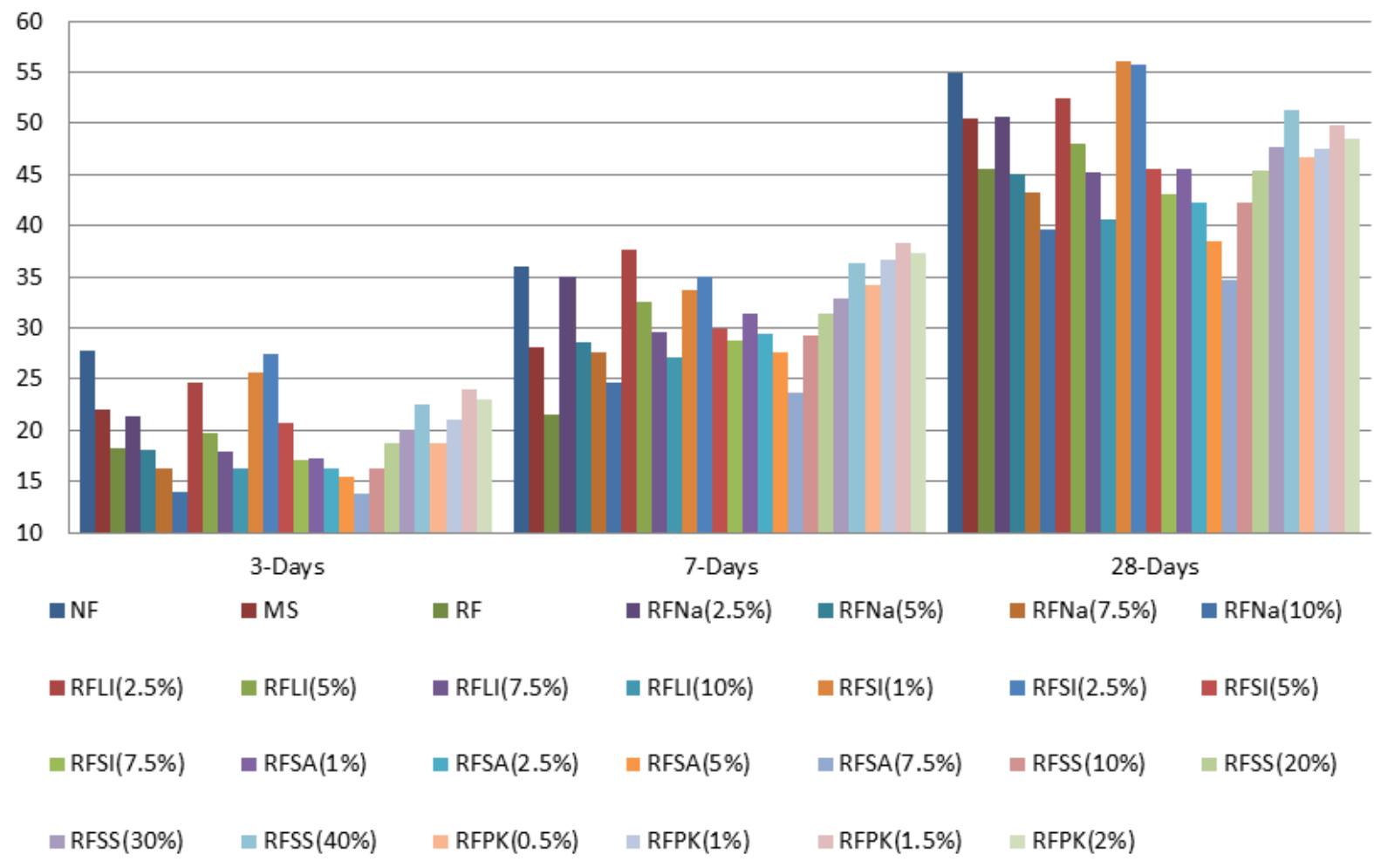

Figure 5. Compressiv Strength (in Mpa) on Cement Mortar Cubes Prepared with Various Types of Fine Aggregates

Based on the above test result data, it can be concluded that the lithium silicate, colloidal silica, and Silane siloxane treatment is effective on Coarse aggregate. And on fine aggregates besides the specific gravity, water absorption test data, the compressive strength test results (As shown in Figure 5) on cement mortar cubes using the different types of aggregates has been used on arriving at the best treatment technique suitable on recycled fine aggregates and from the obtained results it can be interpreted that the Colloidal Silica dioxide (i.e. at a dosage of $1 \%, 2.5 \%$ ) treatment is effective in fine aggregate which may be mainly due to active reaction of colloidal silica with lime present in recycled fine aggregates. Therefore, to know its suitability in concrete application, a combination of treatment has arrived and the same has been compared with the concrete prepared with natural coarse and fine Aggregates and also with untreated recycled coarse and fine aggregates.

Initially, to find/arrive at the best combination, the concrete cubes prepared as per the mix design depicted in Table 03 with the above sorted treated recycled coarse and fine demolished concrete aggregates and tested for their compressive strength, and the results of the cubes were compared with that of concrete made of Natural coarse and fine aggregates and with that of untreated recycled coarse and fine aggregates, the results are depicted in Figure 6. And the same has been used as a reference for arriving at the best combination of treated recycled demolished concrete coarse and fine aggregates in concrete mix and the combination details has been dealt with in detail as below 
Table 3. M30 Grade Concrete Mix Design Using Different Types of Coarse and Fine Aggregates

\begin{tabular}{|c|c|c|c|c|c|c|c|c|c|}
\hline Final Proportion of materials & $\mathrm{NCA}+\mathrm{NFA}$ & $\mathrm{NCA}+\mathrm{M}-$ Sand & $\mathrm{RCA}+\mathrm{RFA}$ & $\begin{array}{c}\text { RCA(2.5\%Li)+ } \\
\text { RFA(2.5\% Si) }\end{array}$ & $\begin{array}{l}\text { RCA(5\% Li) + } \\
\text { RFA(2.5\% Si) }\end{array}$ & $\begin{array}{c}\mathrm{RCA}(2.5 \% \mathrm{Li})+ \\
\mathrm{RFA}(1 \% \mathrm{Si})\end{array}$ & $\begin{array}{c}\text { RCA }(1 \% \mathrm{Si})^{+} \\
\operatorname{RFA}(1 \% \mathrm{Si})\end{array}$ & $\begin{array}{c}\text { RCA(40\%WP)+ } \\
\text { RFA(1\% Si) }\end{array}$ & $\begin{array}{c}\text { RCA(2.5\% Li)+ } \\
\text { RFA(1\% Si) }\end{array}$ \\
\hline Water(Ltr) & 161.278 & 176.65 & 210.14 & 188.61 & 187.6 & 187.21 & 194.85 & 168.69 & 223.98 \\
\hline Cement(kg) & 350.22 & 350.22 & 350.22 & 350.22 & 350.22 & 350.22 & 350.22 & 350.22 & 437.77 \\
\hline${ }^{*}$ Chemical Admixture(Ltr) & 2.98 & 2.98 & 2.98 & 2.98 & 2.98 & 2.98 & 2.98 & 2.98 & 0 \\
\hline Fine Aggregates(kg) & 698.865 & 688.57 & 536.7 & 679.04 & 679 & 673.73 & 673.73 & 673.73 & 613.94 \\
\hline Coarse Aggregate(kg) & 1190.72 & 1190.72 & 1152.94 & 1293.12 & 1313 & 1294.45 & 1268.5 & 1239.51 & 1179.57 \\
\hline
\end{tabular}

*The chemical admixture used is Conplast SP430 (Fosroc) which has Specific Gravity of 1.18, Chloride content nil, and \% of air entrainment is below 2

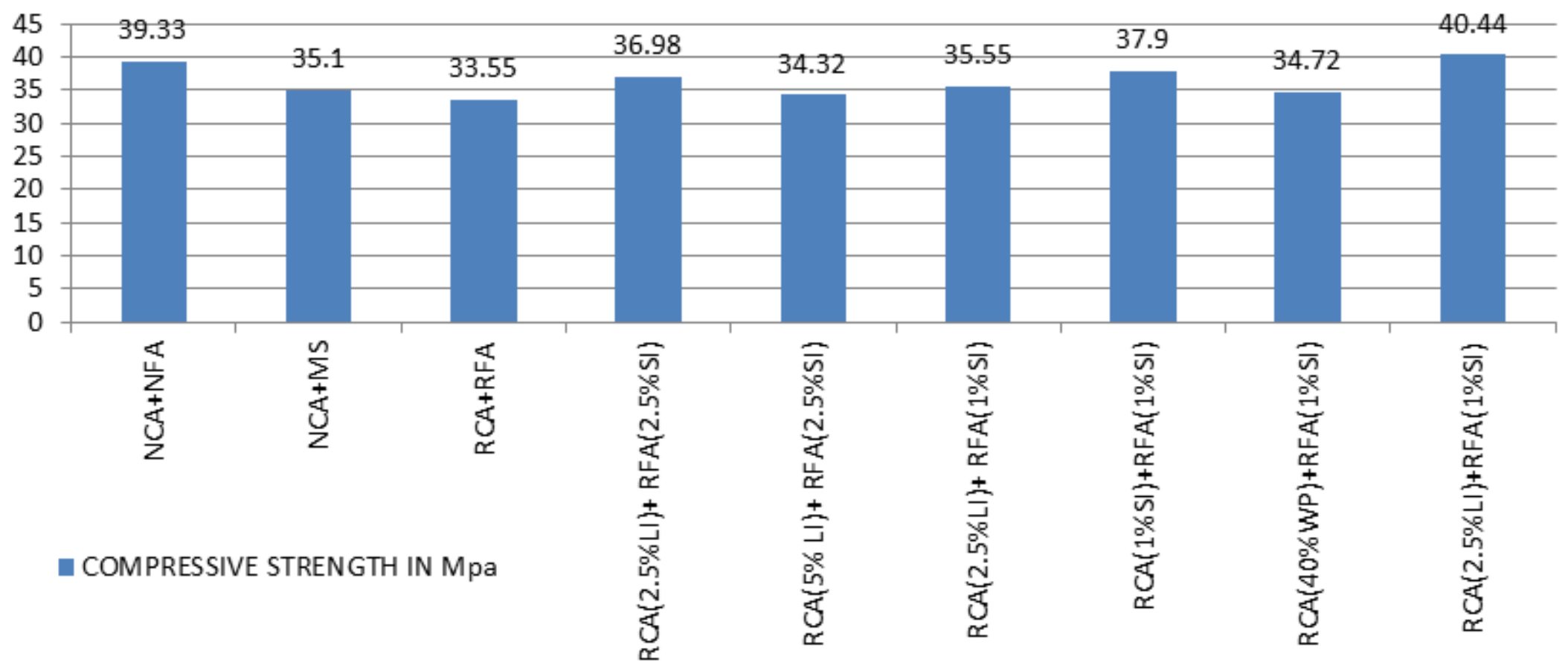

Figure 6. Compressive Strength (in Mpa) of Concrete Cubes Prepared with Various Types of Aggregates 


\subsection{Mechanical Properties Evaluation on Hardened Concrete}

From Figure 6, a combination of $2.5 \%$ of the lithium silicate treatment on a recycled demolished concrete coarse aggregate and $1 \%$ colloidal silica dioxide treatment on demolished concrete fine aggregate was found to have 28-days compressive strength at par with conventional concrete. This treatment was found to be the best treatment for its usage in concrete. Hence, on the same to test its mechanical properties a set of cubes, cylinders and prisms were casted and tested for compressive strength, split tensile strength, flexural strength, shear strength, impact strength and analyses for stress-strain characteristics. And the same was compared with that of cubes casted with natural coarse and fine aggregates and also with recycled coarse and fine aggregate. The results on the same are graphically presented in Figures 7, 8, 9. All the mechanical properties on hardened concrete prepared with treated recycled demolished concrete coarse and fine aggregates (i.e.TRCA is a combination of RCA $(2.5 \% \mathrm{LI})+$ RFA (1\%SI)) have shown improved performance as compared with that of concrete made of untreated recycled aggregates i.e. the concrete prepared with treated recycled coarse and fine aggregates (TRCA) have shown an increase in $2.82 \%$ of the Characteristic compressive strength as compared with that of conventional concrete, similarly, there is an increase in split tensile strength by $3.95 \%$, Flexural strength by $20.8 \%$, shear strength by $21.42 \%$ and impact strength by $3.67 \%$ as compared with that of conventional concrete and, the percentage increase is very much higher as compared with that of concrete prepared with untreated recycled coarse and fine aggregates. Similarly, the stress-strain analysis proves the concrete with TRCA is more elastic and more ductile (i.e. area covered is more in stress-strain cure by treated recycled aggregates) as compared with that of conventional aggregate, and \% of improvement of elasticity is around $3.67 \%$. Further from the compressive strength data as indicated in Figure 7, it can be inferred that compressive strength values of concrete prepared with treated recycled aggregates is low at $3 \& 7$ Days as compared with conventional concrete and thereafter there is an increase in compressive strength at 28 \& 56 days, which shows the slow process of the densification at initial stages and its complete reaction can be seen at $28 \& 56$-days.

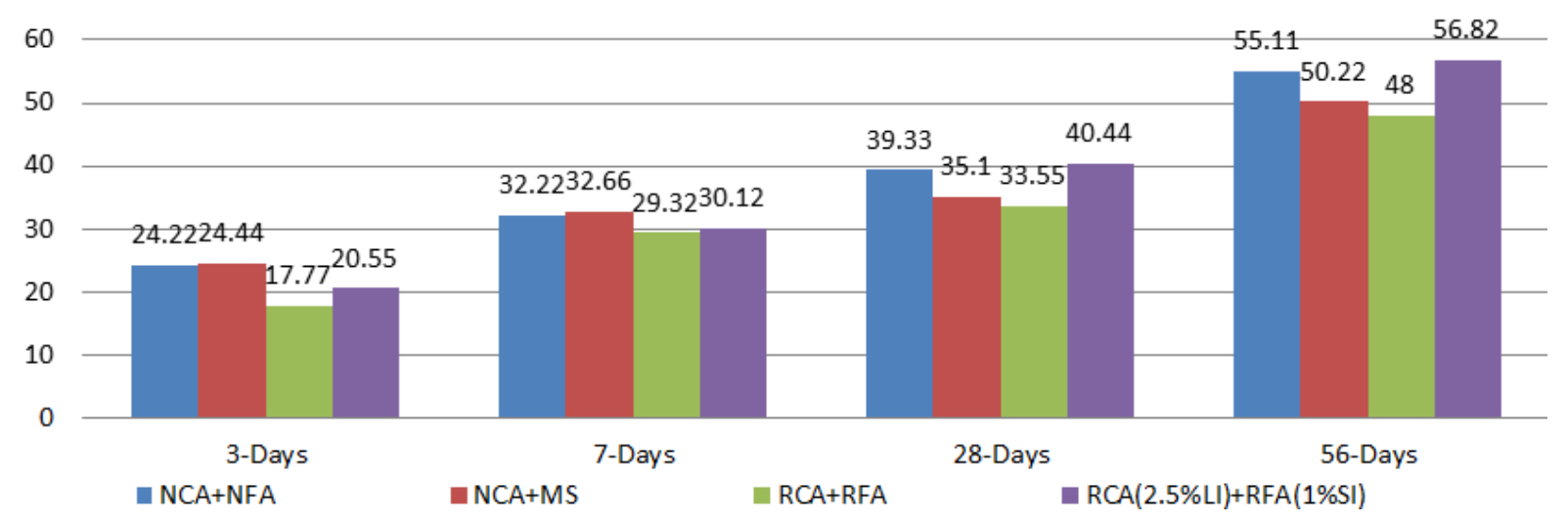

Figure 7. Compressive Strength (in Mpa) of Concrete Cubes Prepared with Various Types of Aggregates based on Best Combination

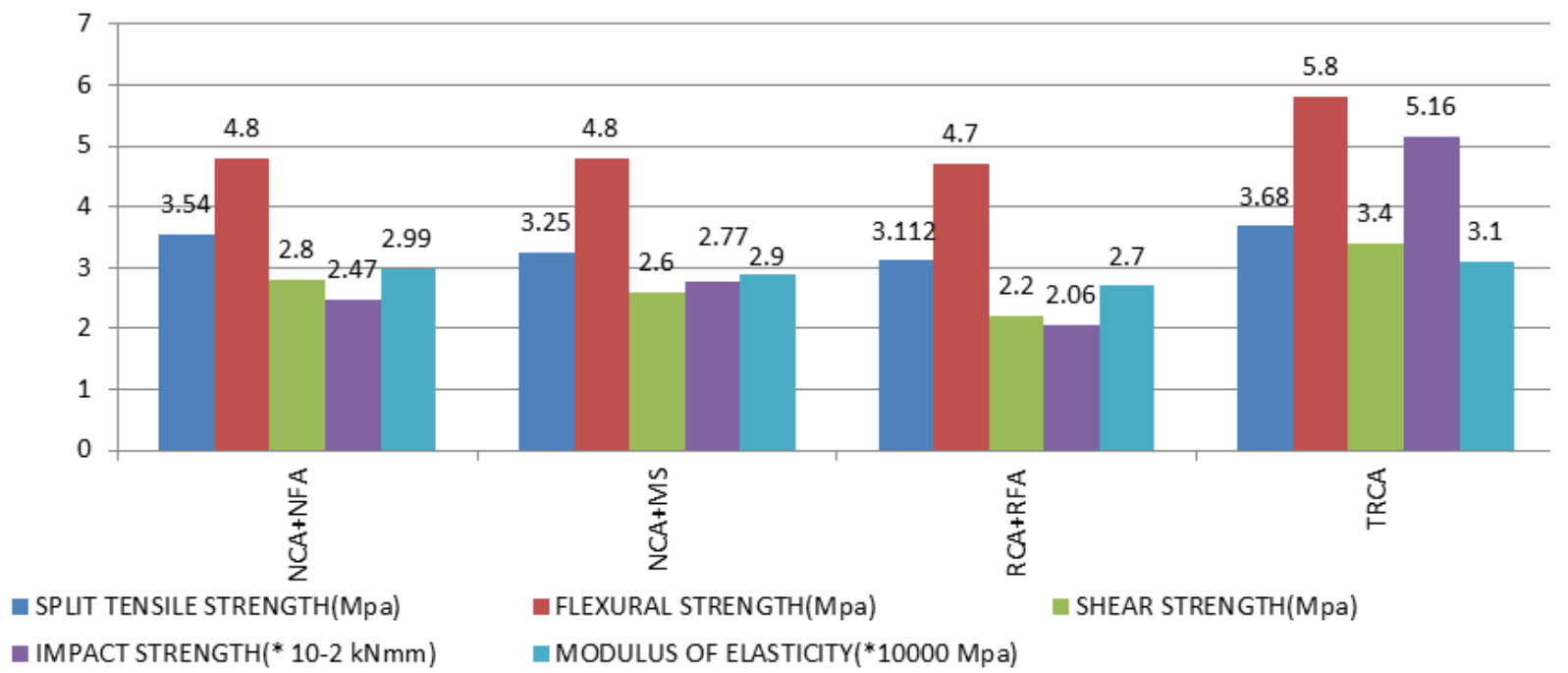

Figure 8. Split Tensile Strength, Flexure Test, Shear Strength, Impact Strength, Modulus of Elasticity Values of Concrete Prepared with Various Aggregates 


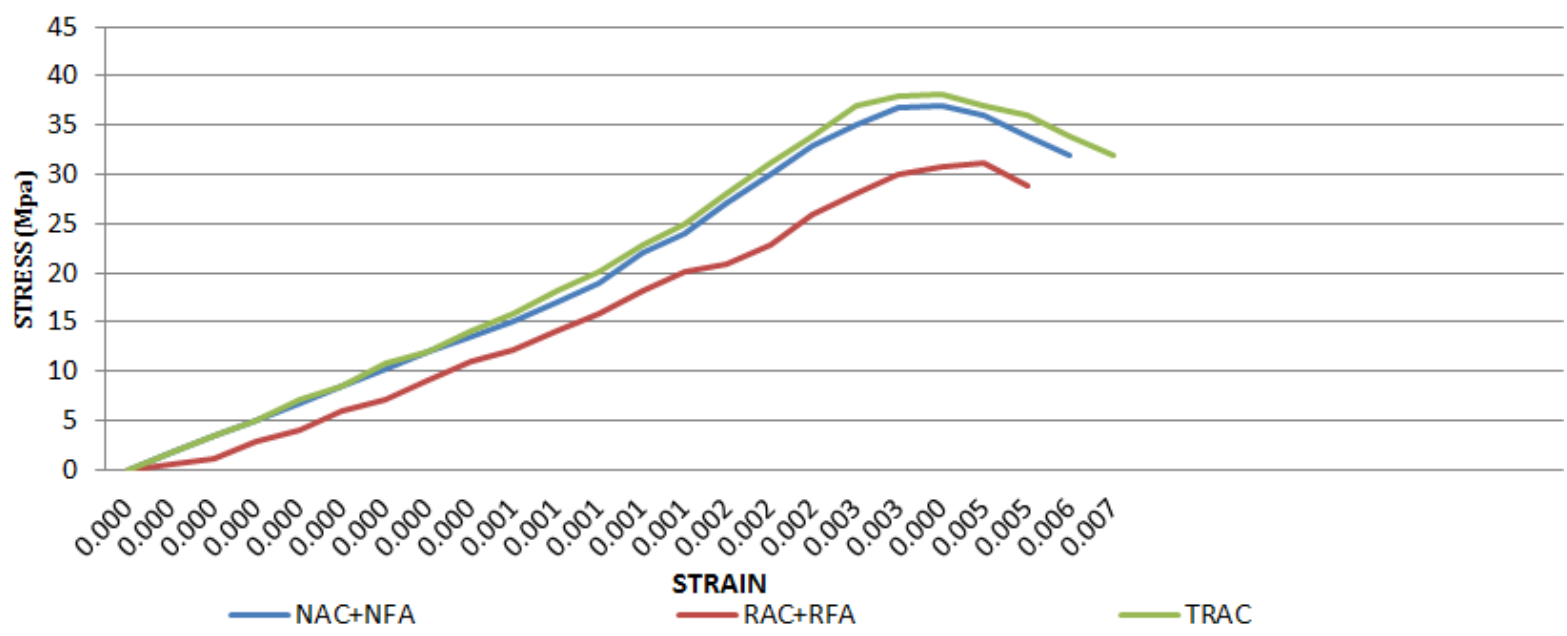

Figure 9. Stress Strain Curve for Monotonic Loading on Concrete Specimen Prepared with Various Aggregates

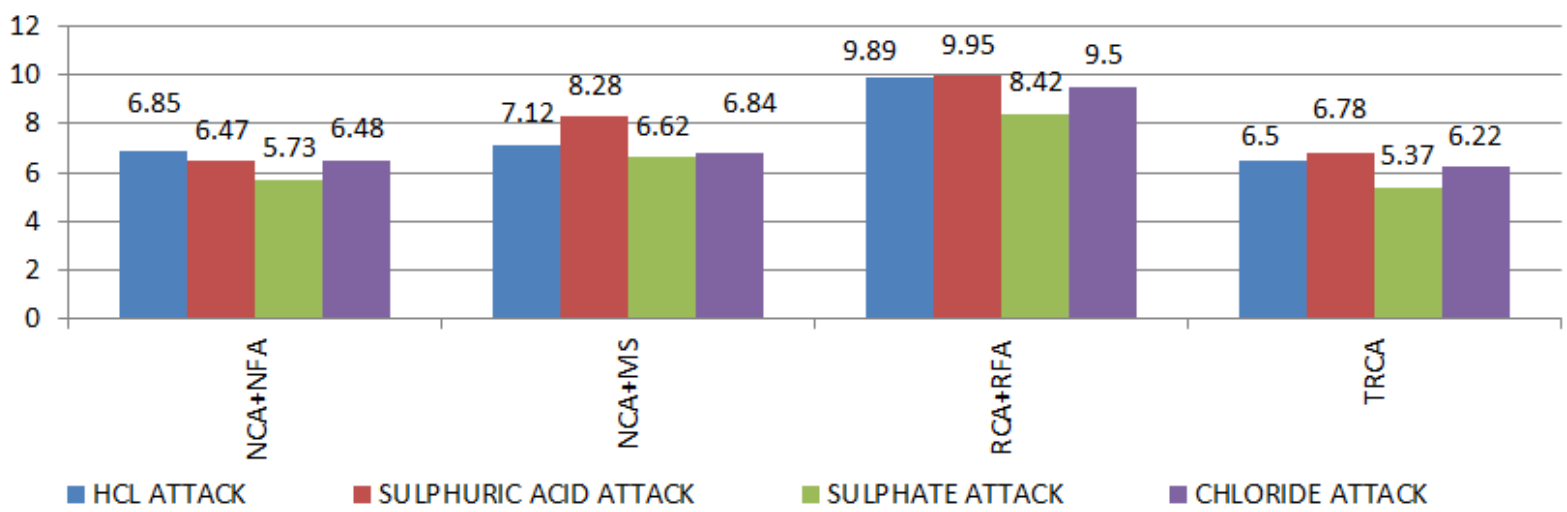

Figure 10. Weight Loss of Concrete Material Subjected to Different Types of Attacks at 180-Days

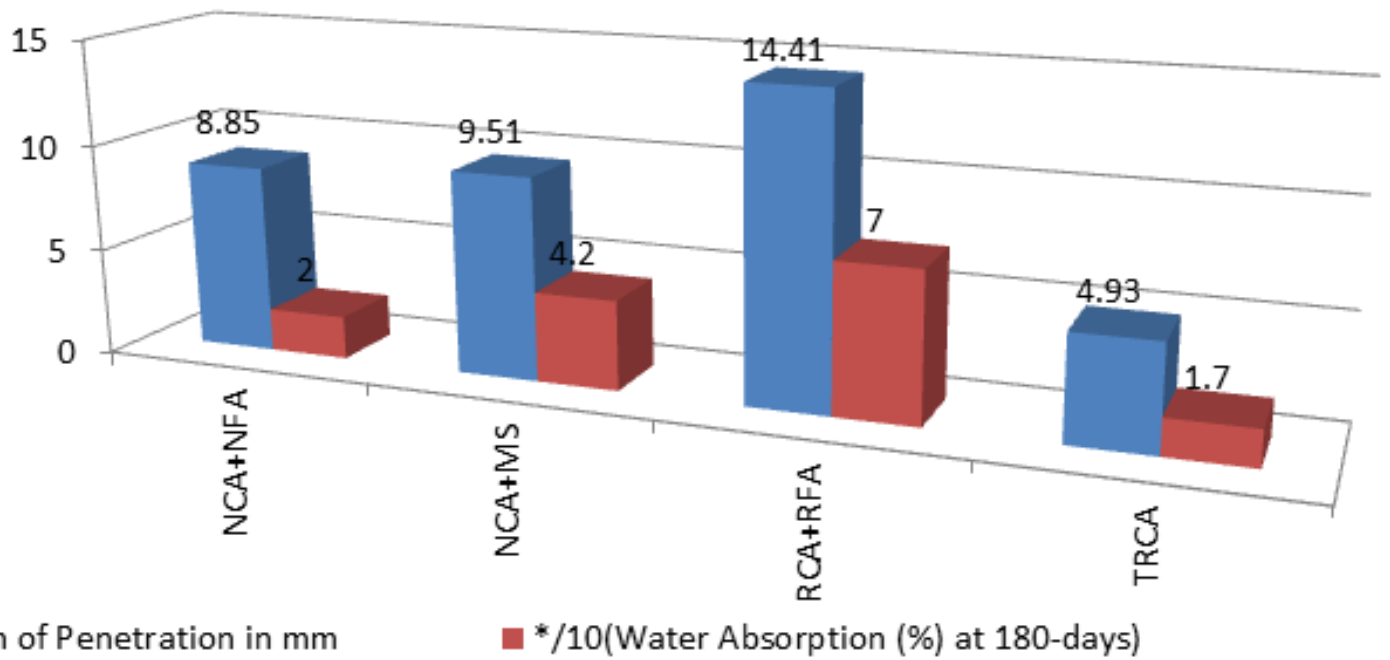

Depth of Penetration in $\mathrm{mm}$

*/10(Water Absorption (\%) at 180-days)

Figure 11. Permeability in Terms of Depth of Penetration (in Mm) and \% of Water Absorption at 180-Days 


\subsection{Durability Study}

Serviceability of concrete prepared with various types of aggregates is assessed by conducting a durability test on concrete by testing its water absorption capacity and its resistance to acid, sulfate, and chloride attacks and also by measuring the permeability of the concrete cubes, the results are as depicted in the figures 10,11 and from the results, it can be inferred that the concrete made of treated recycled demolished concrete coarse and fine aggregates fared well compared with that of untreated recycled aggregates and has superior performance in all serviceability parameters i.e., under Hydrochloric acid attack the resistance is up to $5.4 \%$, under sulfate attack it was about $6.28 \%$ and under the chloride attack it is about $4 \%$, whereas under sulphuric acid attack the resistance levels are within the agreeable limits of $5 \%$. Further, the permeability and water absorption data of concrete prepared with treated aggregates indicated the \% of reduction of pores by $45 \%$ and its resistance to water by $17 \%$ as compared with that of conventional concrete.

\subsection{Microstructural Properties}

Characterizing the mineralogy of the samples can be done in several ways. A few methods such as the Scanning Electron Microscope (SEM) identifies the morphology of the structure, Energy Dispersive Spectroscopy (EDS) allows high-resolution identification of elements and compounds present in prepared 2-D cross-sections of aggregate samples. X-Ray Diffraction (XRD) is also used to identify the compounds and minerals present in powdered specimens and other in detail microstructural details and its analysis. The Microanalysis has been done on the recycled aggregates both treated and untreated aggregates i.e. on both coarse and fine aggregates And on, concrete/mortar masses prepared with the above aggregates along with conventional concrete and the detailed discussion on obtained images /test results values are as dealt below:

\subsubsection{Scanning Electron Microscope (SEM) Analysis}

Through SEM the images of the aggregate sample and cement mortar and concrete sample are taken at various magnifications to identify the Interfacial transition zones and internal particle shape and texture of the particles. The Interfacial Zone formed with treated recycled aggregates in concrete mass is denser as compared with that prepared with untreated recycled aggregates. The below images depict few such locations (Figure 12, 13, 14). (CA-Conventional Coarse and Fine Aggregates, UTRC-Untreated Recycled Demolished Concrete Coarse and Fine Aggregates, TRCA-Treated Recycled Demolished Concrete Coarse and Fine Aggregates)

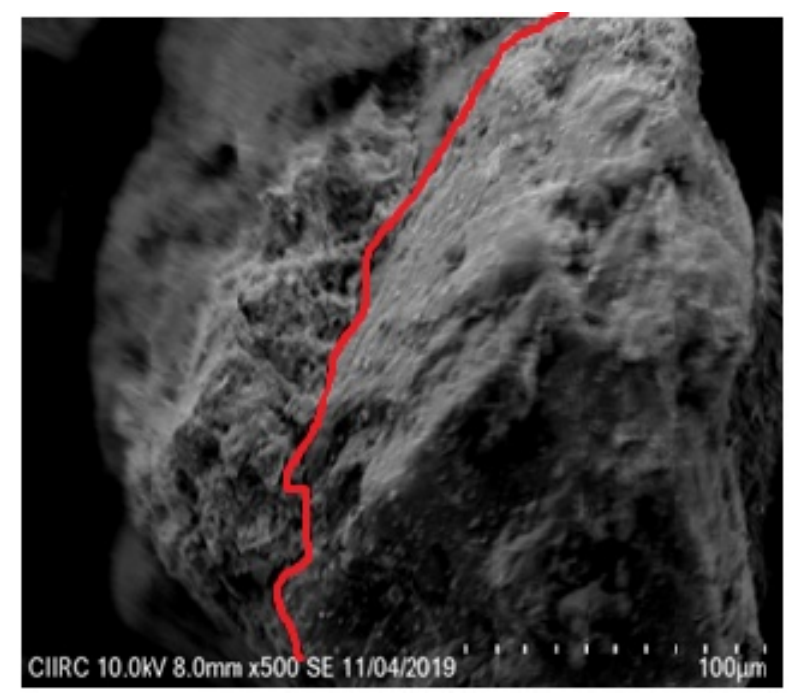

Figure 12. ITZ in Concrete Made of CA

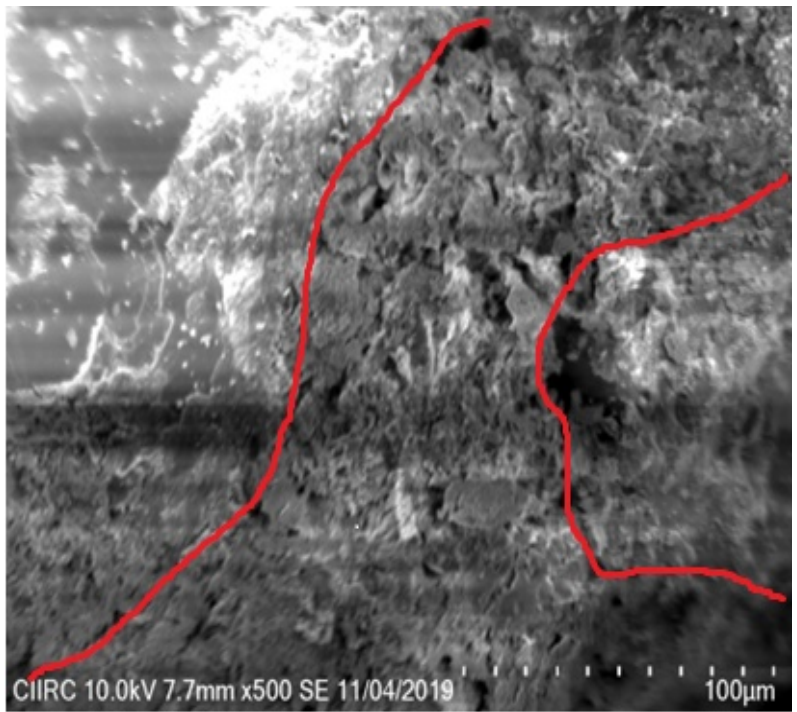

Figure 13. ITZ in Concrete Made of UTRC

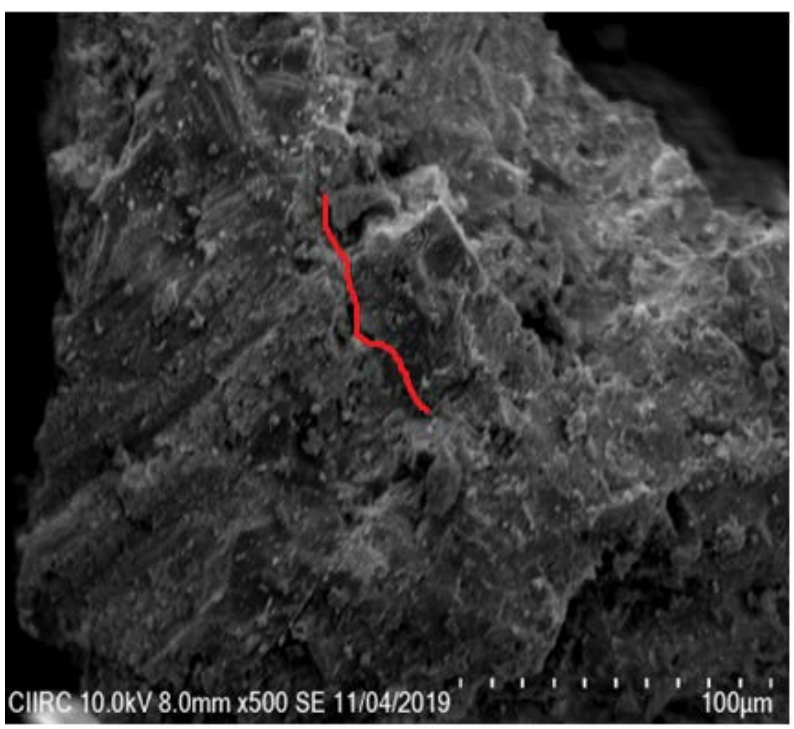

Figure 14. ITZ in Concrete Made of TRCA 
The images of SEM (Figure 15, 16, 17) help in identifying the shapes of the chemical compounds formed and this helps us in understanding the integration of chemical compounds and their orientation in the concrete mass and its defined boundaries. The shape and the chemical components of the internal mass formed are depicted below, and the constituents formed are indicated on the right side. Figure 15 refers to the Concrete made of Natural aggregates where the more formation of $\mathrm{CSH}$, Ettringite, and least formation $\mathrm{Ca}(\mathrm{OH})_{2}$ formation can be seen. The same is quite opposite in the concrete mass prepared with untreated recycled aggregates (i.e. Figure 16). However, concrete prepared with treated aggregates (refer to Figure 17) has shown more formation of CSH and less lime generation. The lime formed is used by silicates in more formation of calcium silicate hydrates, thus justifying the densification process.

The SEM images (Figure 18, 19, 20, 21) on the cement mortar sample prepared with various types of conventional fine aggregates and their chemical compound shapes are depicted below. Here, also in the conventional mortar, more formation of $\mathrm{CSH}$, Ettringite and lime can be seen (Refer Figure 18, 20). In mortar samples prepared with recycled fine aggregates has resulted in more formation of lime rather than CSH (Refer Figure 19). However, the mortar prepared with treated recycled fine aggregates has shown the significant formation of CSH (Refer Figure 21) which may be mainly due to the presence of colloidal silica which reacts with the hydrated lime resulting in more formation of CSH.

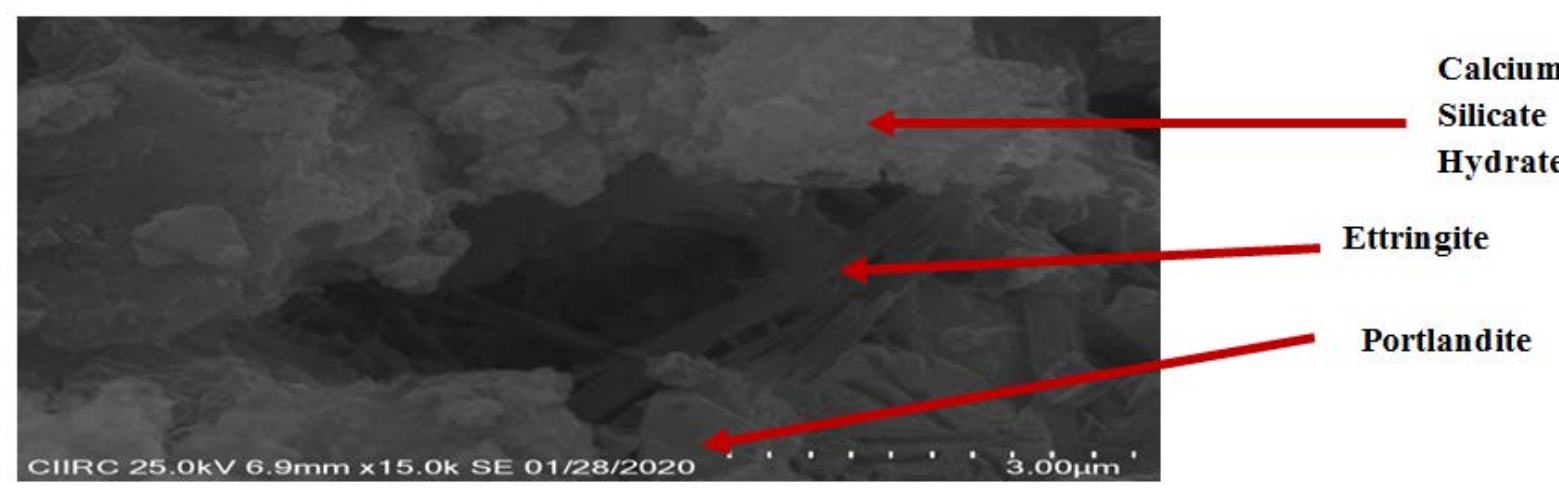

Figure 15. Internal Chemical Compound Structure of Concrete Made of Natural Aggregates

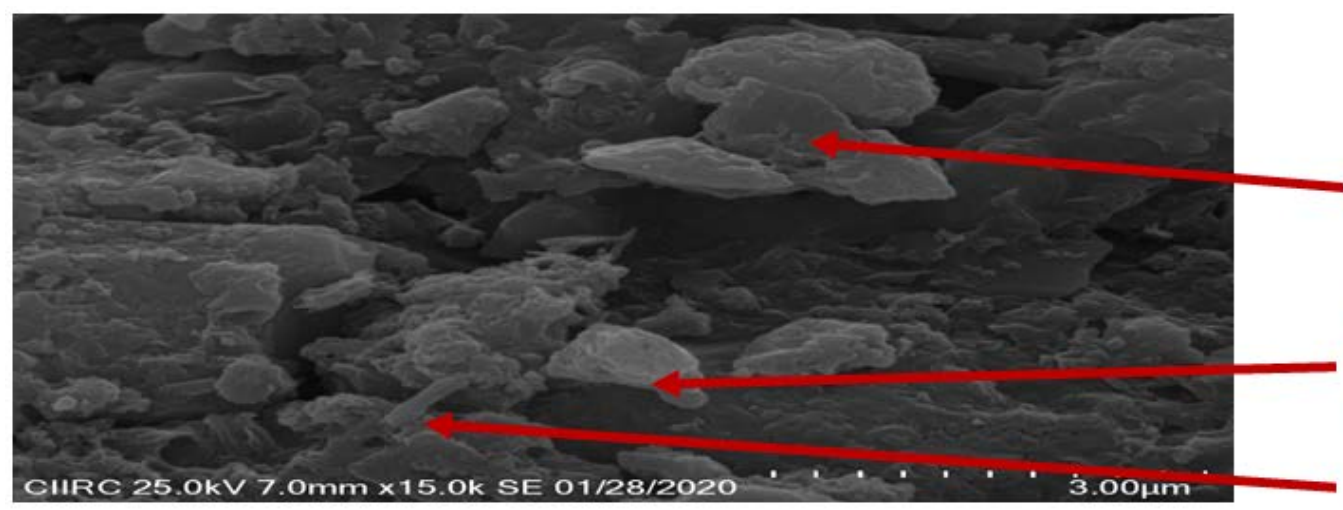

Portlandite

Calcium

Silicate

Hydrate

Ettringite

Figure 16. Internal Chemical Compound Structure of Concrete Made of Untreated Aggregates

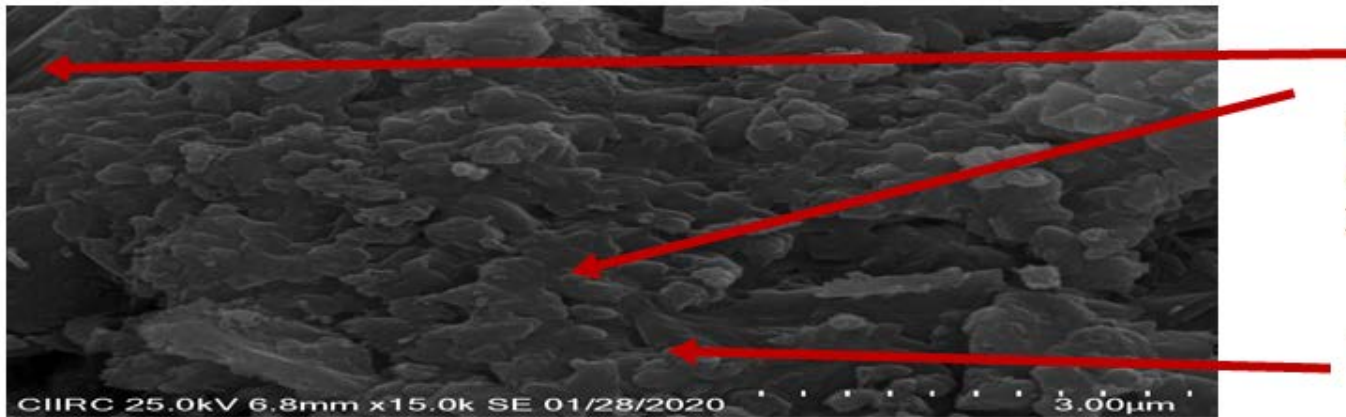

Ettringite

Calcium

Silicate

Hydrate

Lithium

Figure 17. Internal Chemical Compound Structure of Concrete Made of Treated Aggregates 


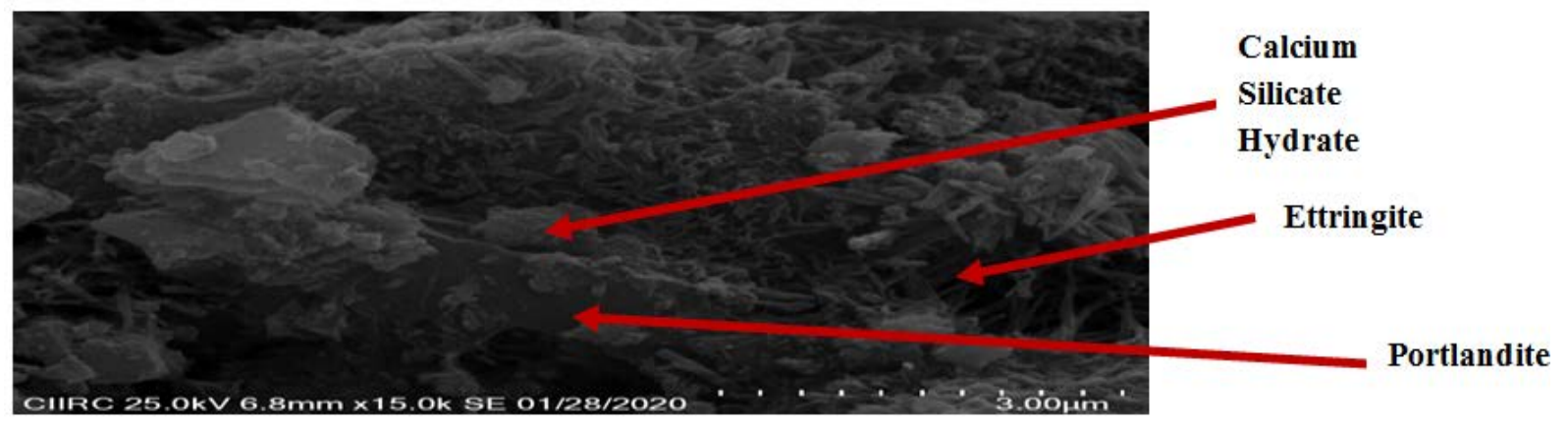

Figure 18. Internal Chemical Compound Structure of Mortar Made of Natural Aggregates

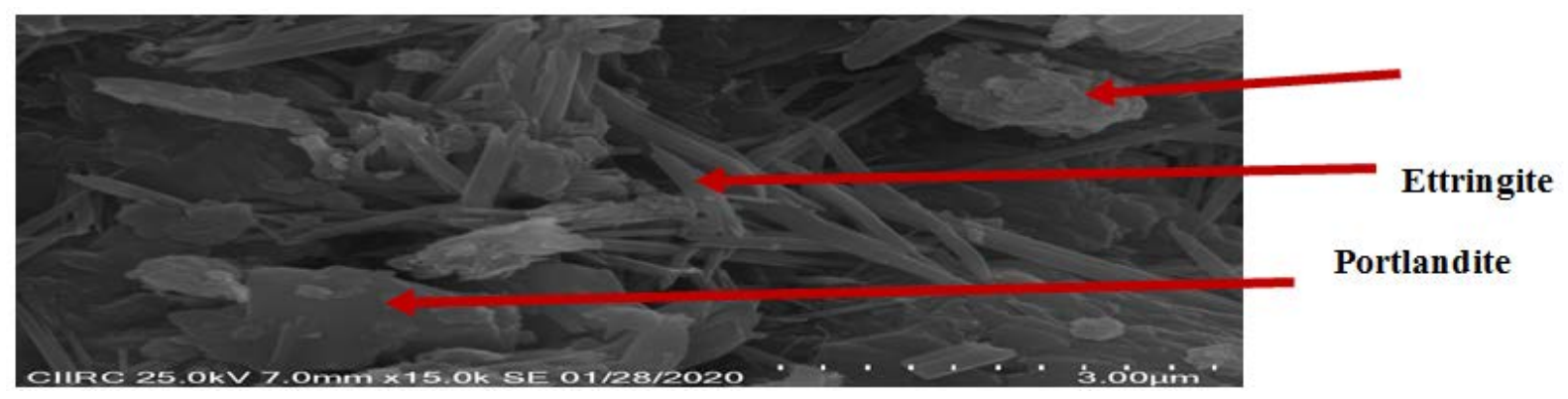

Figure 19. Internal Chemical Compound Structure of Mortar Made of Untreated Aggregates

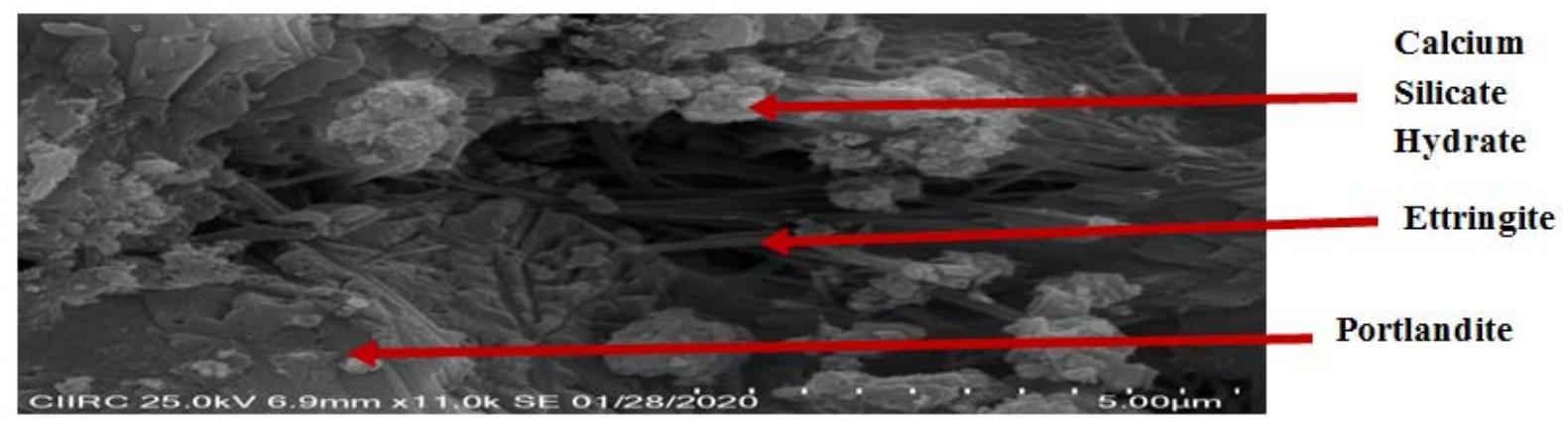

Figure 20. Internal Chemical Compound Structure of Mortar Made of M-Sand

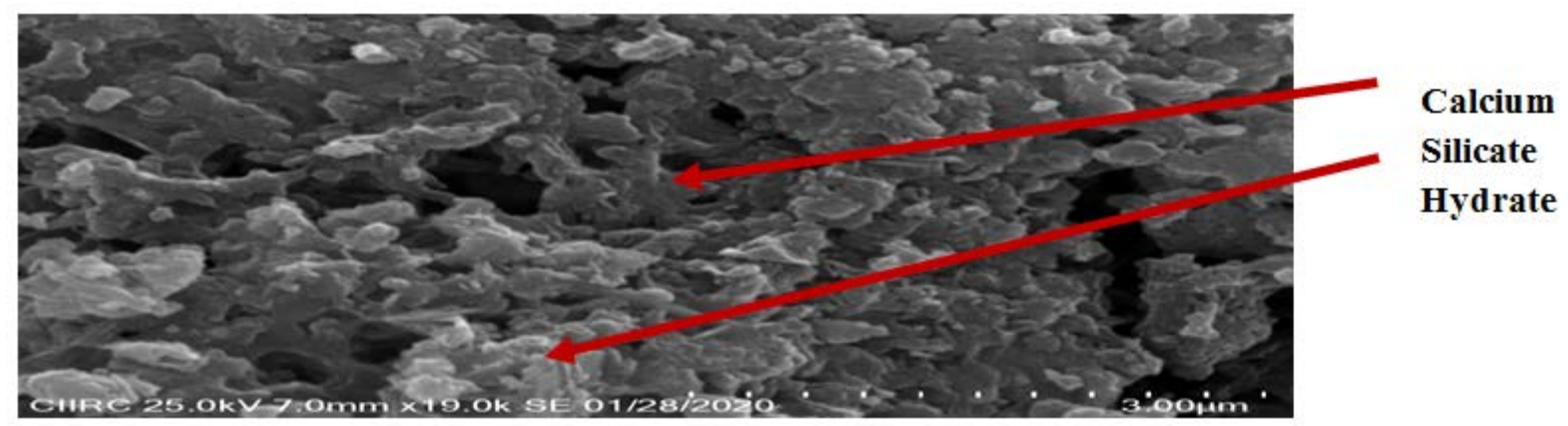

Figure 21. Internal Chemical Compound Structure of Mortar Made of Treated Aggregates

\subsubsection{Energy Dispersive Spectroscopy (EDs) Analysis}

Energy Dispersive (EDs) analysis was carried out to determine the elemental composition of treated aggregates and untreated aggregates and on concrete masses. Spectra were acquired with the help of INCA systems software that is used by the Oxford spectrometer. The detailed summary of the chemical compounds formed in the treated aggregates and untreated aggregates, and in the concrete/mortar mass prepared with conventional aggregates and with that prepared with untreated/treated recycled aggregates is as below. From figure 22, 23, 24 \& 25 the chemical components after treatment on coarse and fine aggregate have shown an increase in calcium silicate content it can be inferred to Figure 32 shows the chemicals 
components formed before and after treatment and which indicates the treatment adopted has used excess lime present in the untreated aggregates in the densification of the aggregate mass in treated aggregates, the peaks of the calcium and silica so formed can be seen in the figures. If we consider the ratio of 1:3 of calcium hydroxide and calcium silicate hydrate ratio in the hydration process. From Figure 26 to 28, it can be interpreted that the silica content associated with calcium in conventional aggregate is around $41.20 \%$ and with untreated aggregates, treated aggregates it is around $21.01 \%$ and $67.61 \%$, which indicates more formation of calcium silicate in the concrete prepared with treated recycled demolished concrete aggregates as compared with that of concrete made of conventional aggregates and with that of untreated recycled demolished concrete aggregates. The case is similar in cement mortar cubes as shown in Figures 29 to
31. Figures 32 and 33 depict the $\mathrm{Ca} / \mathrm{Si}$ ratio and Content of $\mathrm{Na}$ formed and present in the mass, which indicates the treated aggregates and the concrete/mortar mass prepared with these aggregates have resulted in the least formation of portlandite i.e. \% of formation is to the extent of $36 \%$ less as compared with that of conventional concrete. And also least presence of sodium indicates that the stable nature of the Calcium silicate formed in the concrete prepared with treated aggregates as compared with that of conventional concrete (TCA-Treated Recycled Coarse Aggregate, UTCA-Untreated Recycled Coarse Aggregate, TFA-Treated Recycled Fine Aggregate, UTFA-Untreated Recycled Fine Aggregate, CCA-Conventional Concrete, CTA-Concrete prepared with Treated Aggregates, CUTA-Concrete prepared with untreated aggregates, MCFA-Conventional Mortar Cubes).

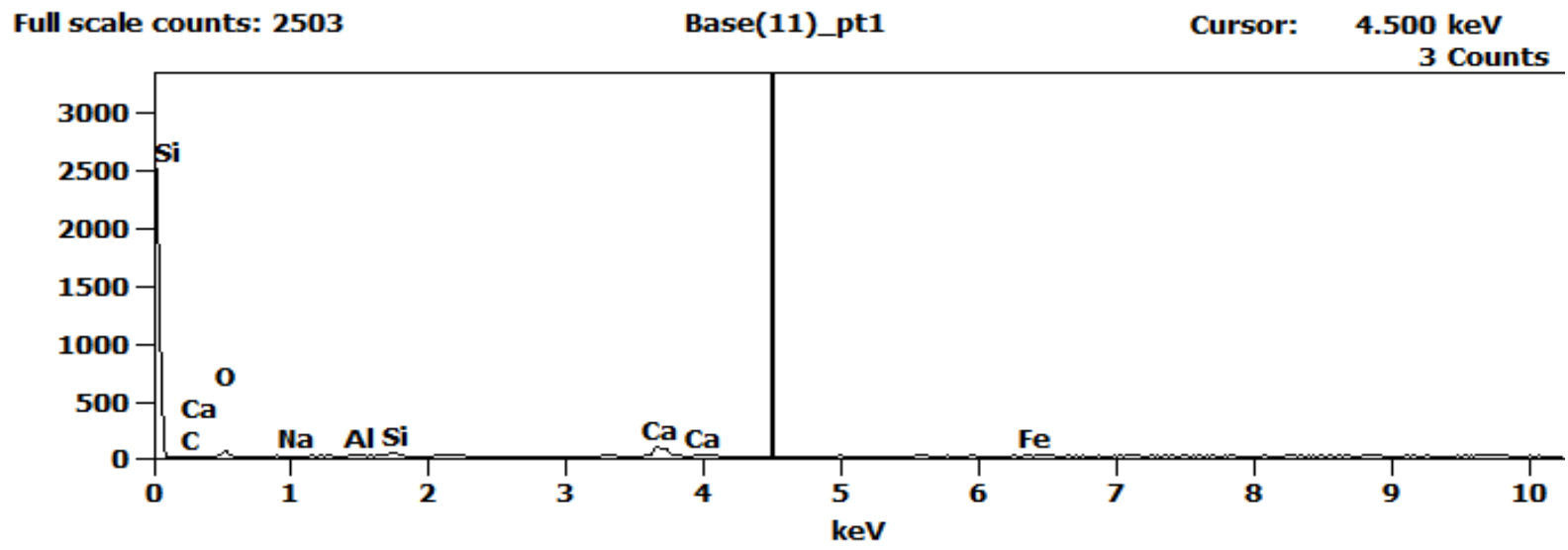

Figure 22. EDS data On Untreated Coarse Aggregates

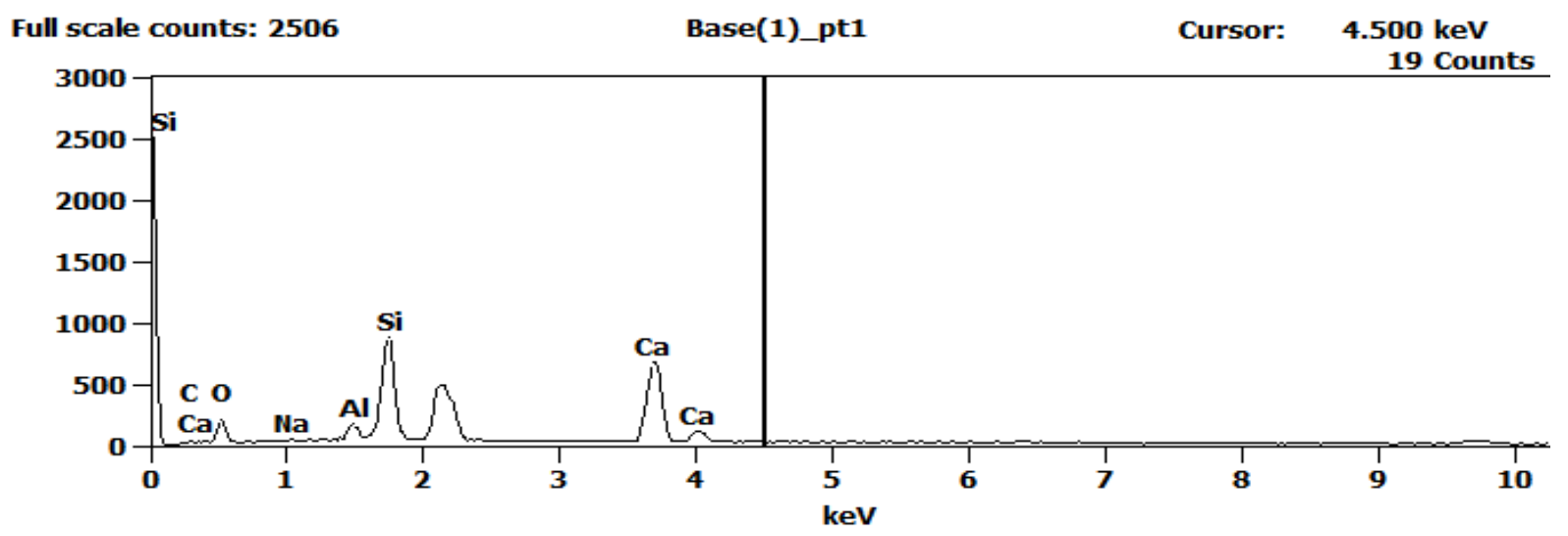

Figure 23. EDS data On Treated Coarse Aggregates 


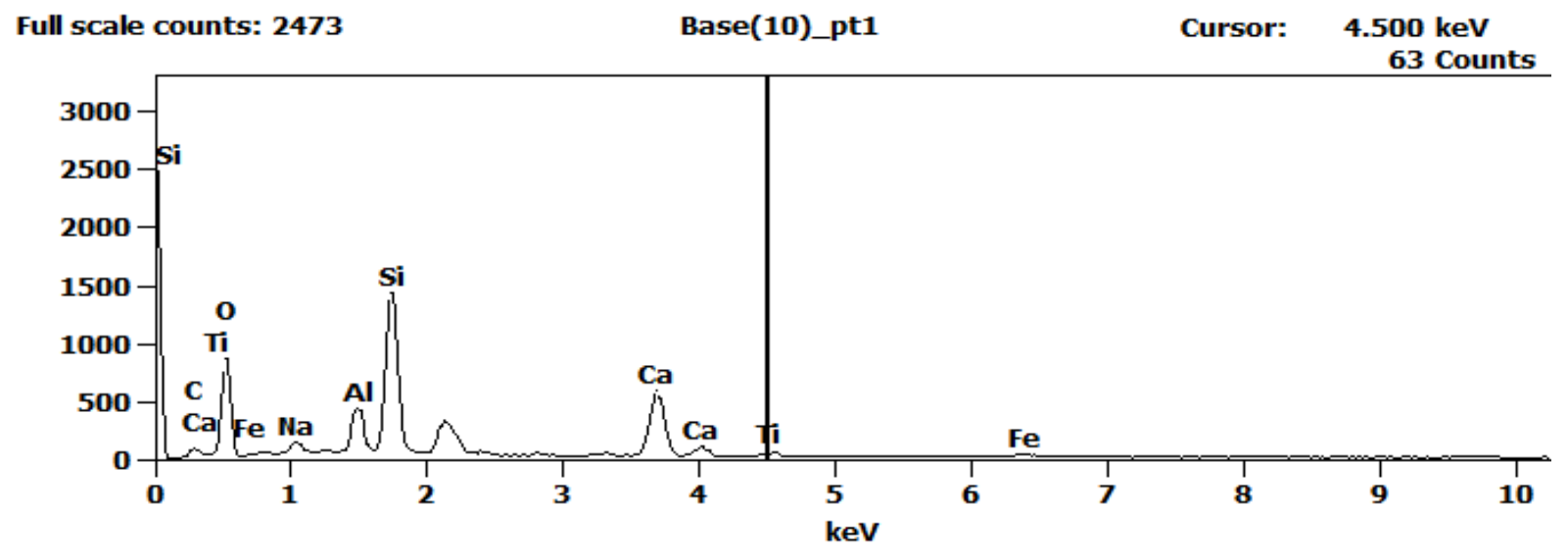

Figure 24. EDS data On Untreated Fine Aggregates

Full scale counts: $\mathbf{5 1 7 4}$

Base(5)_pt1

Cursor:

$4.500 \mathrm{keV}$

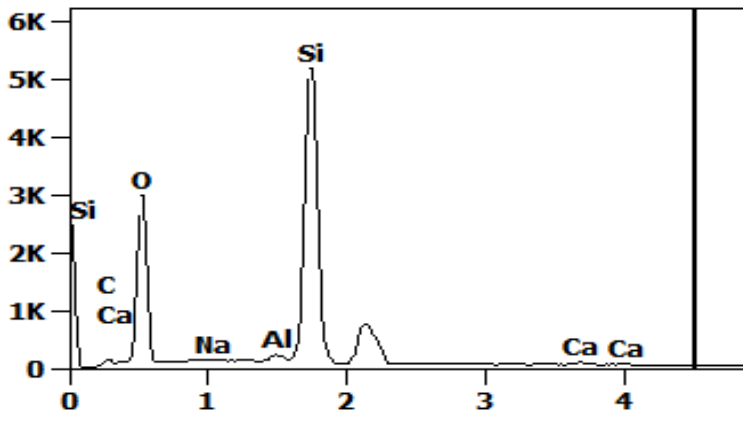

26 Counts

Figure 25. EDS data On Treated Fine Aggregates

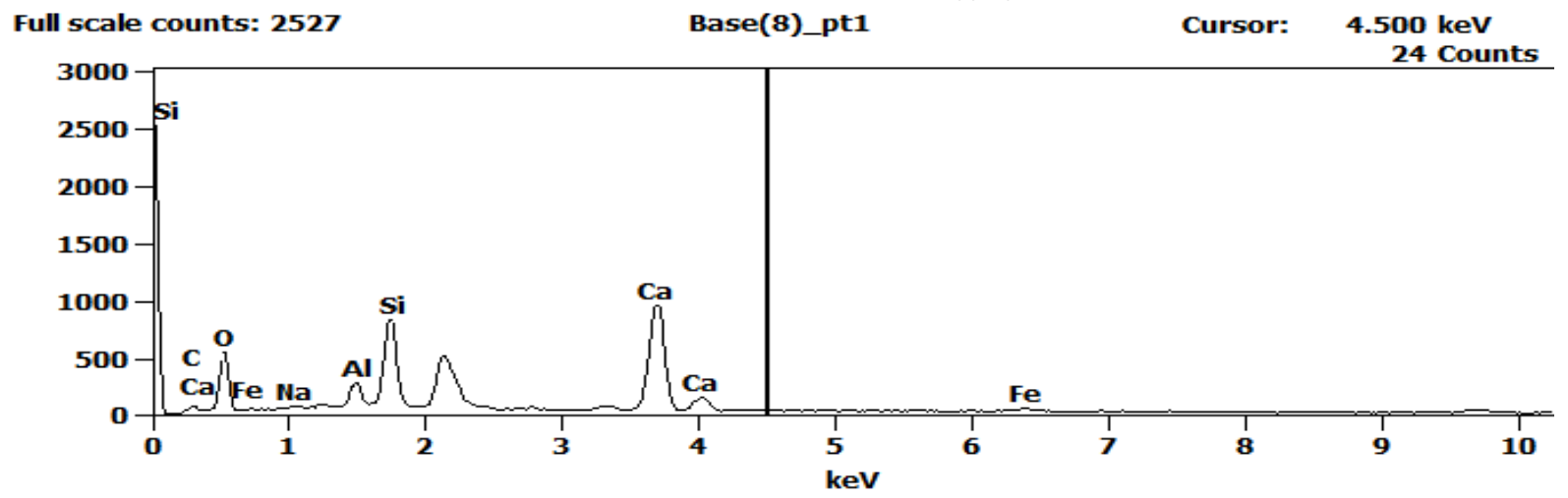

Figure 26. EDS data For Concrete Casted With Natural Coarse and Fine Aggregates

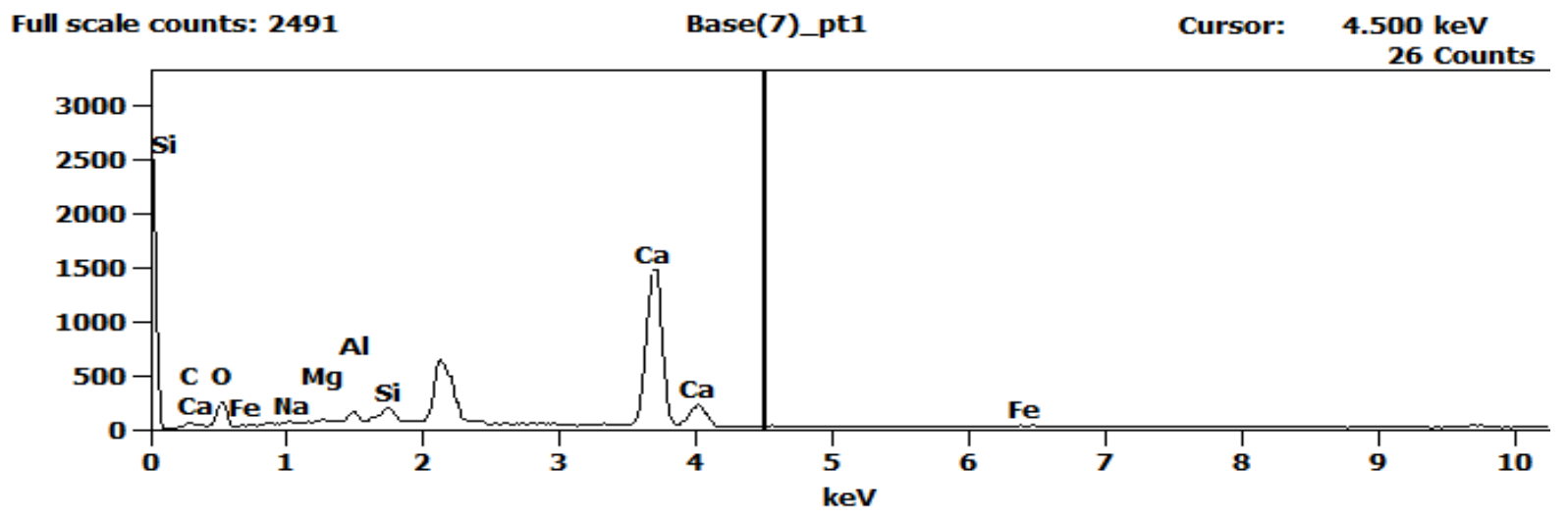

Figure 27. EDS data For Concrete Casted With Recycled Coarse and Fine Aggregates 


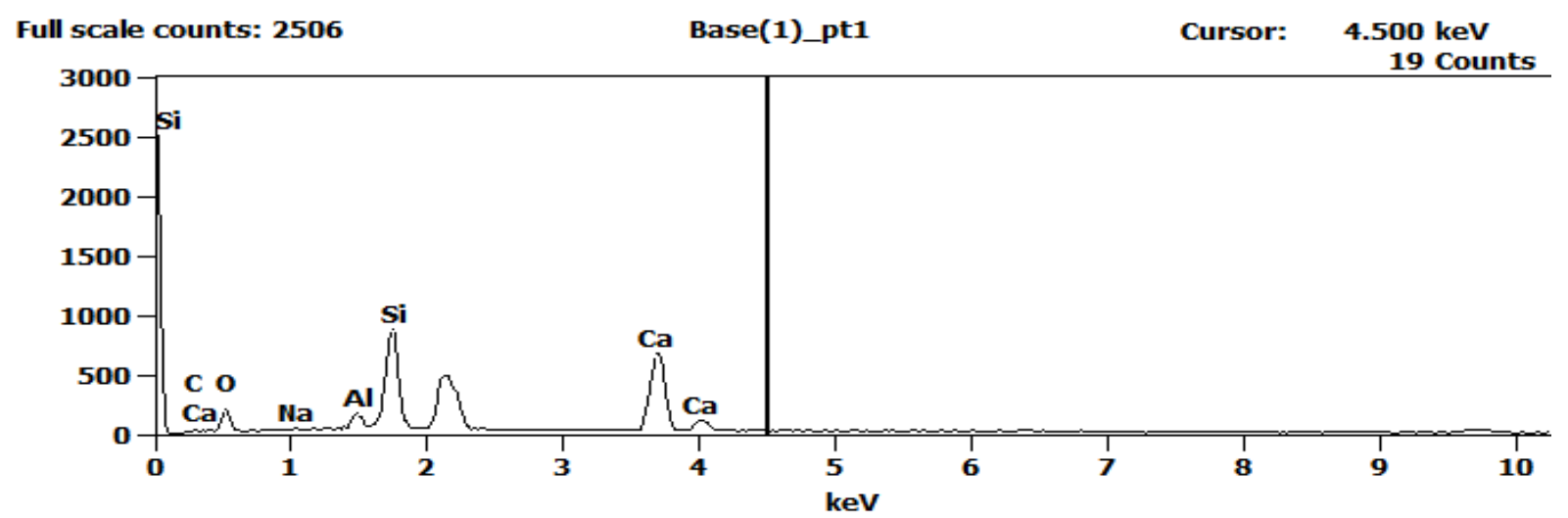

Figure 28. EDS data For Concrete Casted With Treated Recycled Coarse and Fine Aggregates

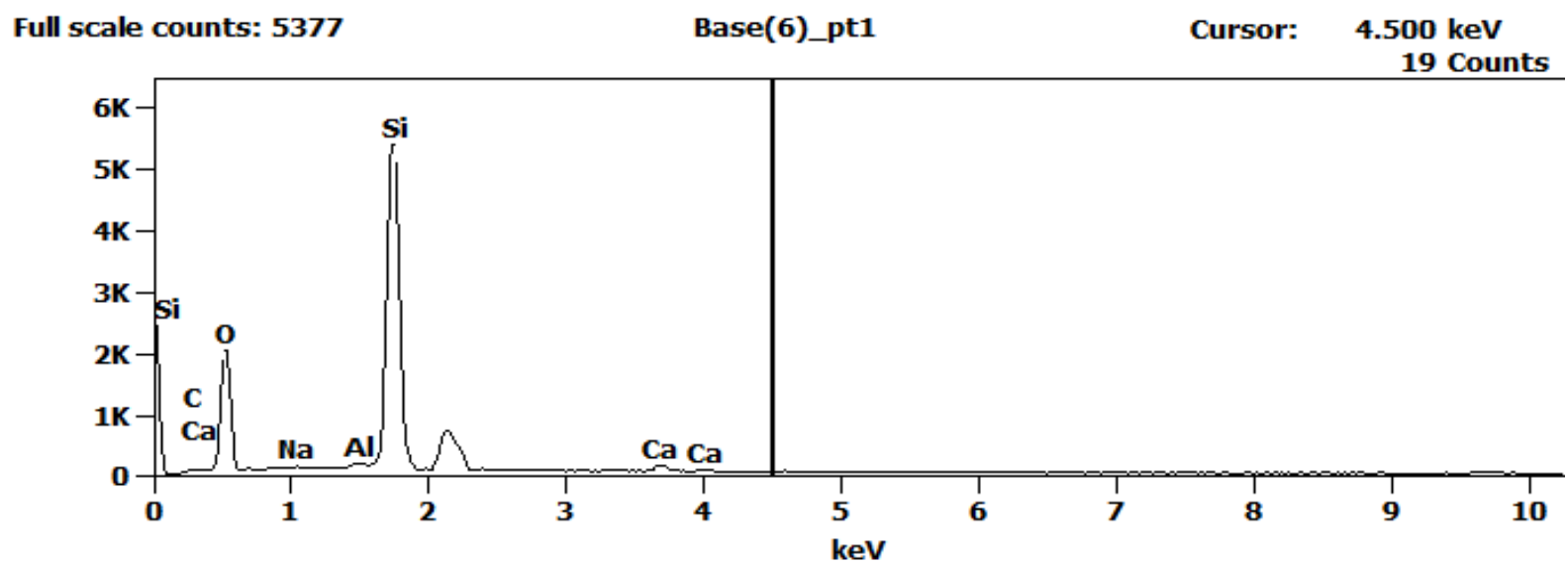

Figure 29. EDS data on Mortar Cubes casted with Treated Fine Aggregates

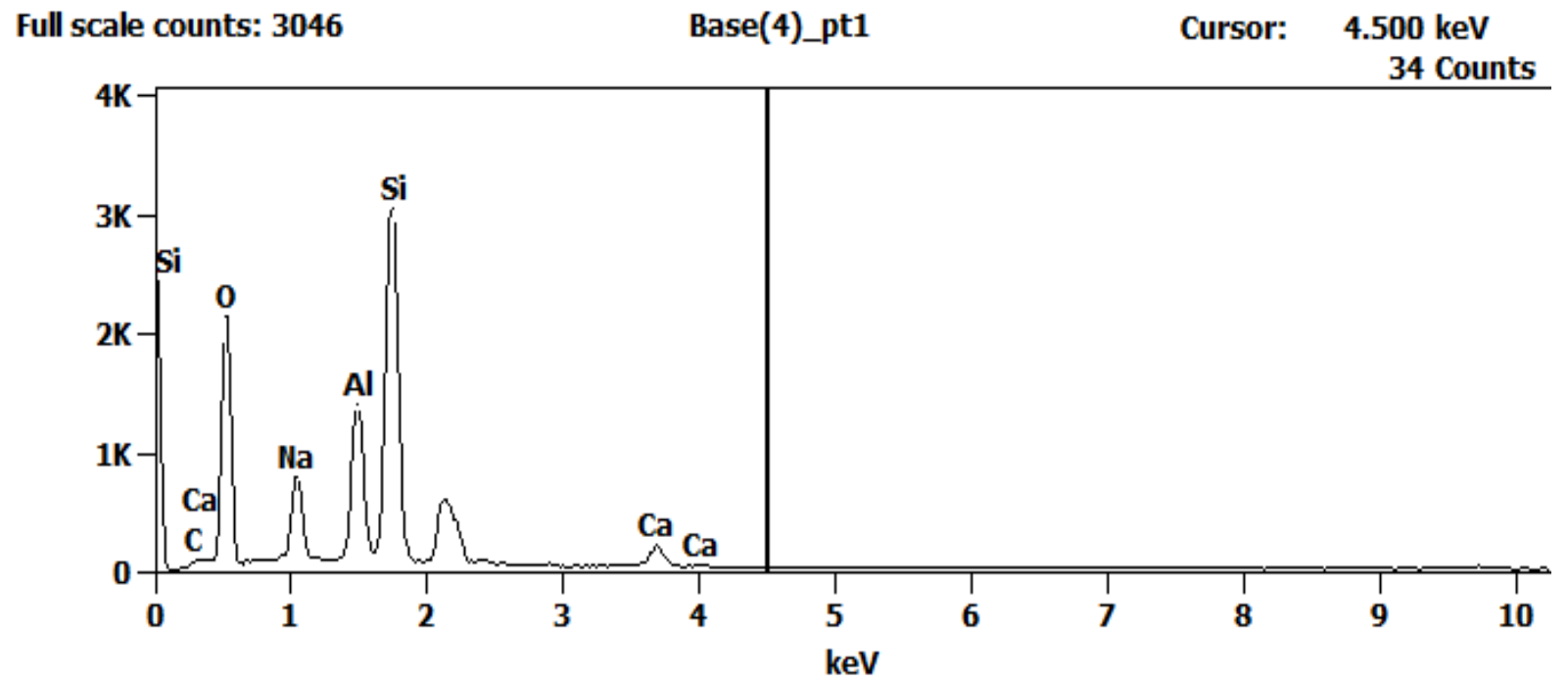

Figure 30. EDS data on Mortar Cubes casted with Natural Fine Aggregates 
Full scale counts: 2431

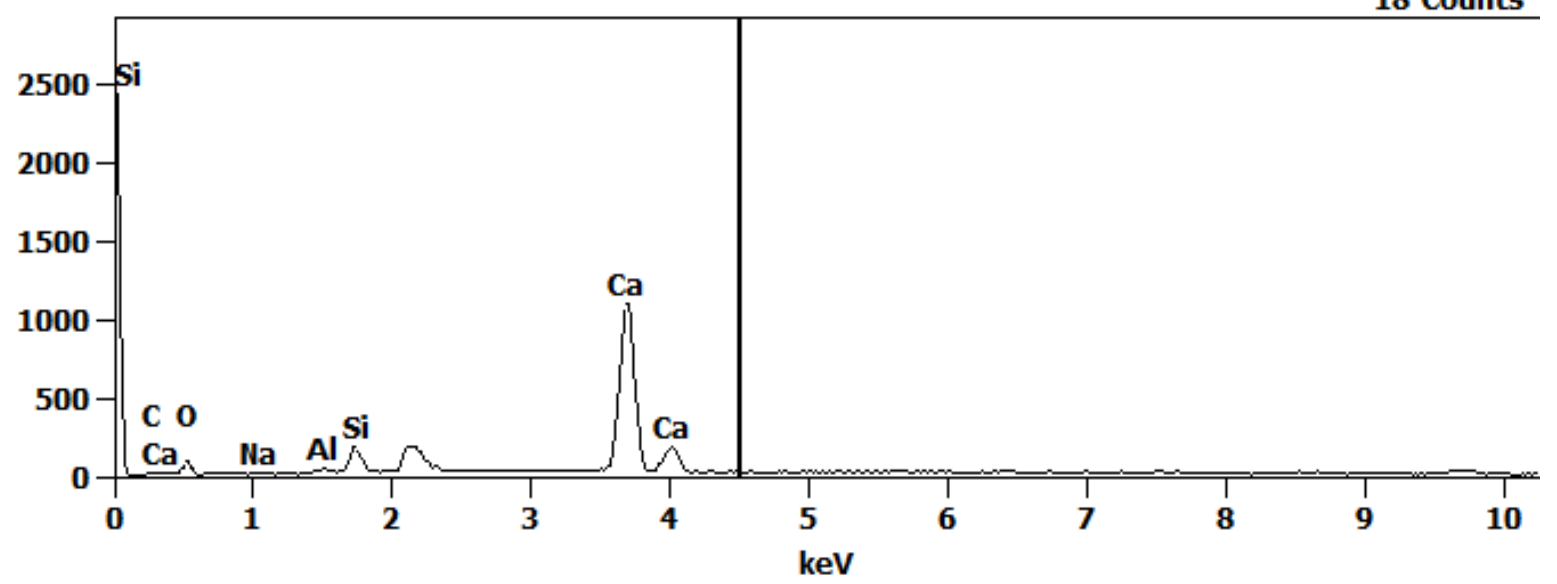

Figure 31. EDS data on Mortar Cubes casted with Untreated Fine Aggregates

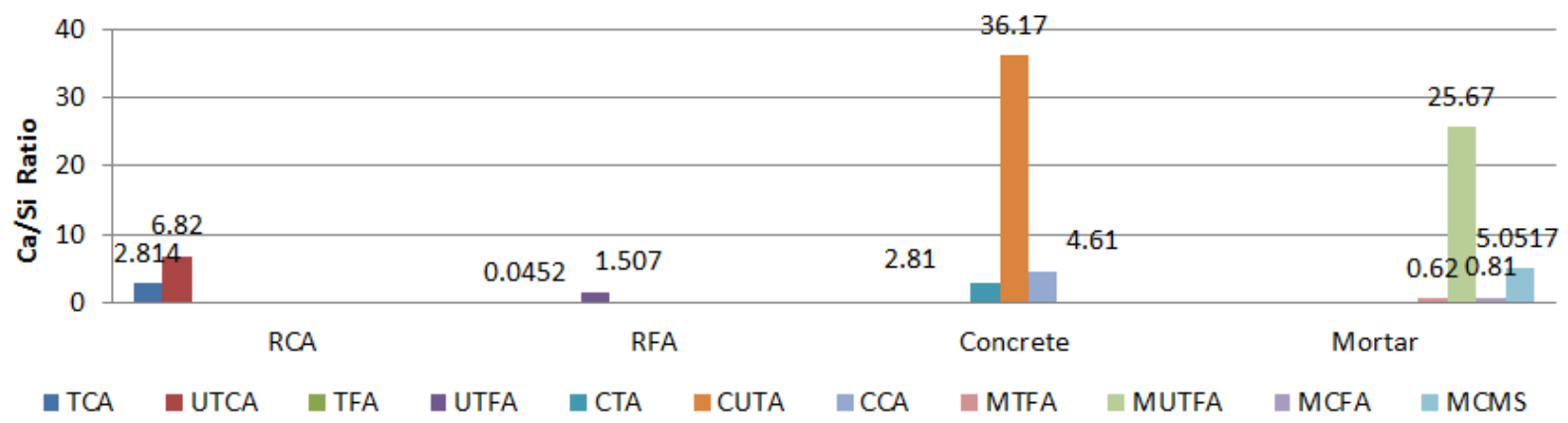

Figure 32. $\mathrm{Ca} / \mathrm{Si}$ ratio of Different Samples Under Test

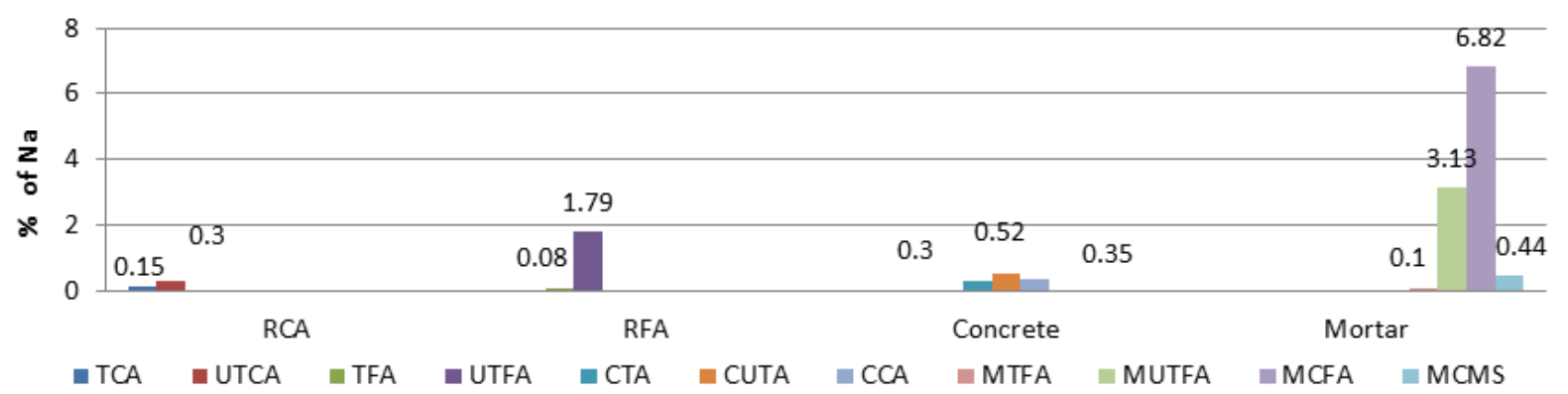

Figure 33. Presence of $\%$ of Sodium in Different Samples under Test

\subsubsection{XRD Analysis}

Mineralogical composition of aggregate, concrete \& mortar mass has been determined on few grams of the sample using a diffractometer with Co-Ka radiation anticathode. XRD diffraction is a powerful tool in the identification of the mineralogical crystal composition, crystal structure, and its internal behavior. Mainly the $\mathrm{XRD}$ is done to identify the following parameters,

a). Phase Identification: - The diffraction pattern for every phase is as unique as our fingerprint. Phases with the same chemical composition can have drastically different diffraction patterns. The position and relative intensity of a series of peaks are used to match experimental data to the reference patterns in the database. The phase identification has been done by using the XRD data and by using Match software and a few details of which are depicted in Figures 34, 35 for concrete/mortar mass prepared with treated aggregates. The chemical compounds formed are mainly:

b). Quantity of Phase Identification: - The Match software helps in assessing the formation of \% of the Chemical compound formed from the XRD diffraction data and the data gathered on the different specimens, the details of the same are shown in Figure 34,35.From

c). Percentage of Crystallinity: - The XRD diffraction data helps in identifying whether the material is a crystalline, semi-crystalline, or amorphous nature. Table 
04 depicts the \% of crystalline formed in the aggregate samples and the concrete/mortar mass.

d). Crystallite Size: - Crystallite size is normally defined as a size of a single crystal within a polycrystalline solid. Crystallites are smaller than $\sim 120 \mathrm{~nm}$ create broadening of diffraction peaks - this peak broadening can be used to quantify the average crystallite size of nano-particles using the Scherrer equation. In table 01 , the details of the size of the crystal lattice formed are depicted.

e). Distortional density: - Dislocation density is a measure of the number of dislocations in a unit volume of a crystalline material and XRD patterns help us in the identification of the distortional density formed in the aggregate and in the concrete/mortar mass, the details of the same are presented in Table.02

f). Structure Determination: - In crystallography, crystal structure is a description of the ordered arrangement of atoms, ions, or molecules in a crystalline material. The XRD patterns help us calculate the shape of the molecular arrangement, by way of unit cell parameters and which was done by using Match software. The calculation helps in the identification of the molecular arrangement. The obtained data reveal that treatment methodology employed on the aggregate surface has caused major changes in its molecular arrangement and the molecular structure has changed its orientation from trigonal to monoclinic and making the arrangement of the molecular planes in an inclined manner. The change is mainly due to the formation of calcium Silicate which has a monoclinic structure. The quartz, lime, and calcite which are on the recycled demolished concrete aggregate surface area having a trigonal structure. Further, the concrete /mortar prepared with treated aggregates has a more multimolecular structure i.e., a combination of monoclinic, triclinic, trigonal, cubic arrangements of crystal molecules in its mass which indicates dense packing of molecules. Concrete prepared with conventional aggregates and with recycled aggregates has a combination of two structures i.e., trigonal and triclinic of the arrangement of crystal molecules. These make the crystal arrangement loose and induce more pores and voids.

Table 4. Overall the Internal Microphysical Parameter Details of Different Materials as Tested under XRD

\begin{tabular}{|c|c|c|c|c|c|}
\hline Description of Material & Crystalline size(nm) & d-Spacing $(\mathrm{nm})$ & $\begin{array}{c}\text { Distortion } \\
\text { Density }\left(1 / \mathrm{nm}^{2}\right)\end{array}$ & $\begin{array}{c}\text { MicroStrain } \\
\left(\mathrm{x} 10^{-2}\right)\end{array}$ & $\begin{array}{c}\text { \% of } \\
\text { Crystallinity }\end{array}$ \\
\hline $\begin{array}{c}\text { Untreated Recycled Coarse } \\
\text { Aggregate Concrete }\end{array}$ & 34.90526576 & 0.022857671 & 0.103925649 & 0.012581075 & 68.97720014 \\
\hline $\begin{array}{c}\text { Treated Recycled Coarse } \\
\text { Aggregate Concrete }\end{array}$ & 33.83667901 & 0.022183917 & 0.006078683 & 0.005562016 & 77.18576604 \\
\hline $\begin{array}{c}\text { Untreated Recycled Demolished } \\
\text { Concrete Fine Aggregate } \\
\text { Concrete }\end{array}$ & 35.35304729 & 0.019839572 & 0.001571846 & 0.006553249 & 93.37424457 \\
\hline $\begin{array}{c}\text { Treated Recycled Demolished } \\
\text { Concrete Aggregate Concrete }\end{array}$ & 33.49897278 & 0.021408658 & 0.014545589 & 0.008023648 & 97.37281409 \\
\hline $\begin{array}{c}\text { Concrete Prepared With } \\
\text { Conventional Aggregate }\end{array}$ & 26.11642007 & 0.017352654 & 0.052204601 & 0.012007008 & 88.18886718 \\
\hline $\begin{array}{c}\text { Concrete Prepared With } \\
\text { Untreated Recycled Demolished } \\
\text { Concrete Aggregates }\end{array}$ & 44.89173805 & 0.029120422 & 0.00081124 & 0.002830977 & 34.8603164 \\
\hline $\begin{array}{c}\text { Concrete Prepared With Treated } \\
\text { Recycled Demolished Concrete } \\
\text { Aggregate }\end{array}$ & 32.17371812 & 0.016574234 & 0.004443825 & 0.004571332 & 96.39610023 \\
\hline Mortar with Natural sand & 37.68698157 & 0.024616483 & 0.001356228 & 0.003109678 & 78.13954892 \\
\hline Mortar Prepared with M -sand & 84.23167158 & 0.045503865 & 0.000375591 & 0.001826313 & 89.03102656 \\
\hline $\begin{array}{c}\text { Mortar Prepared with Untreated } \\
\text { Recycled Demolished Concrete } \\
\text { Fine Aggregate }\end{array}$ & 43.05912722 & 0.027931188 & 0.001853823 & 0.002826553 & 65.75841894 \\
\hline $\begin{array}{c}\text { Mortar Prepared with Treated } \\
\text { Recycled Demolished Concrete } \\
\text { Fine Aggregate }\end{array}$ & 35.79601339 & 0.02367313 & 0.001574846 & 0.003177291 & 99.89450129 \\
\hline
\end{tabular}




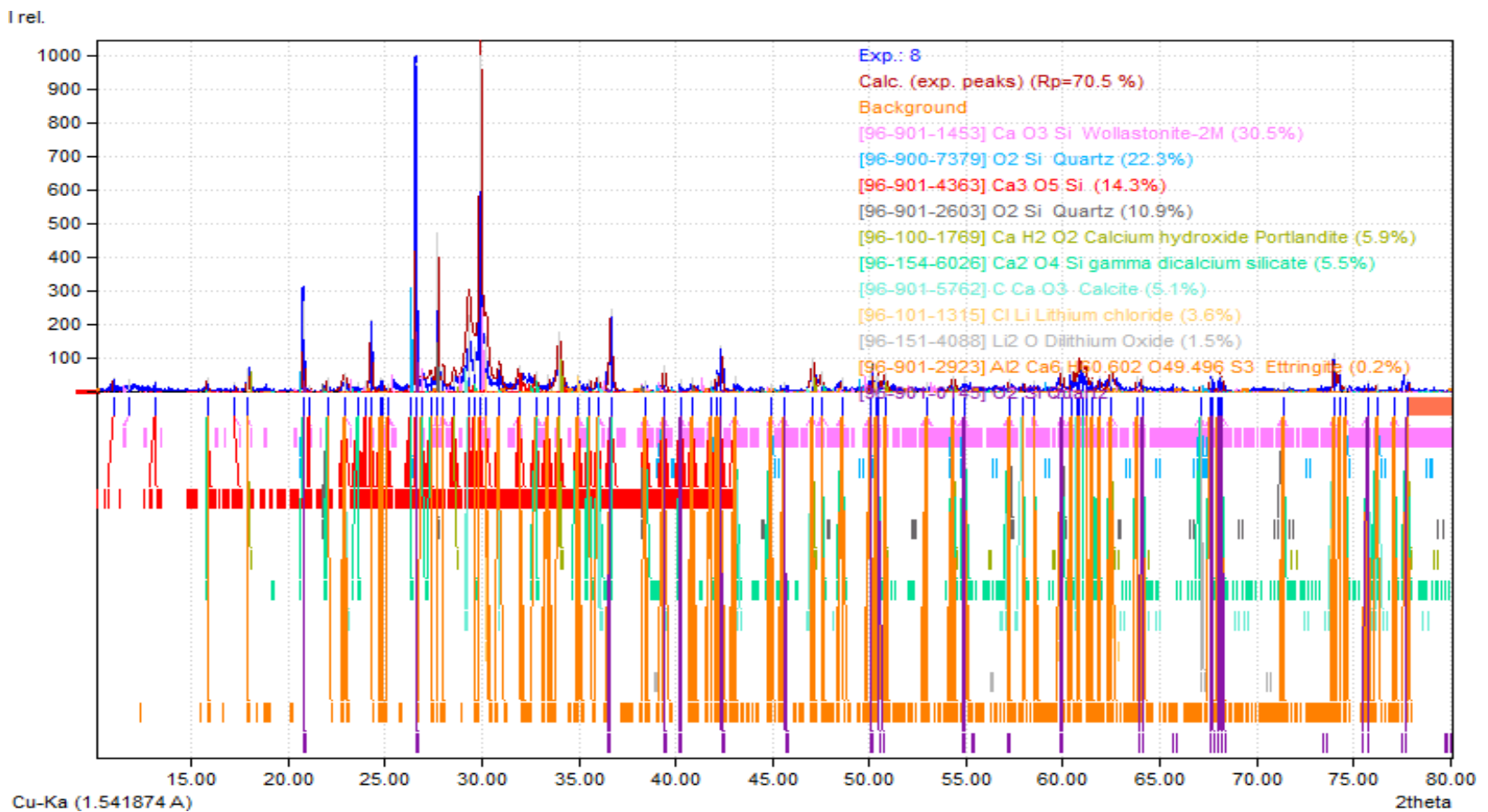

Figure 34. Diffraction Pattern Graph of Concrete SPECIMEN Prepared With Treated Recycled Demolished ConCrete Coarse and Fine Aggregates

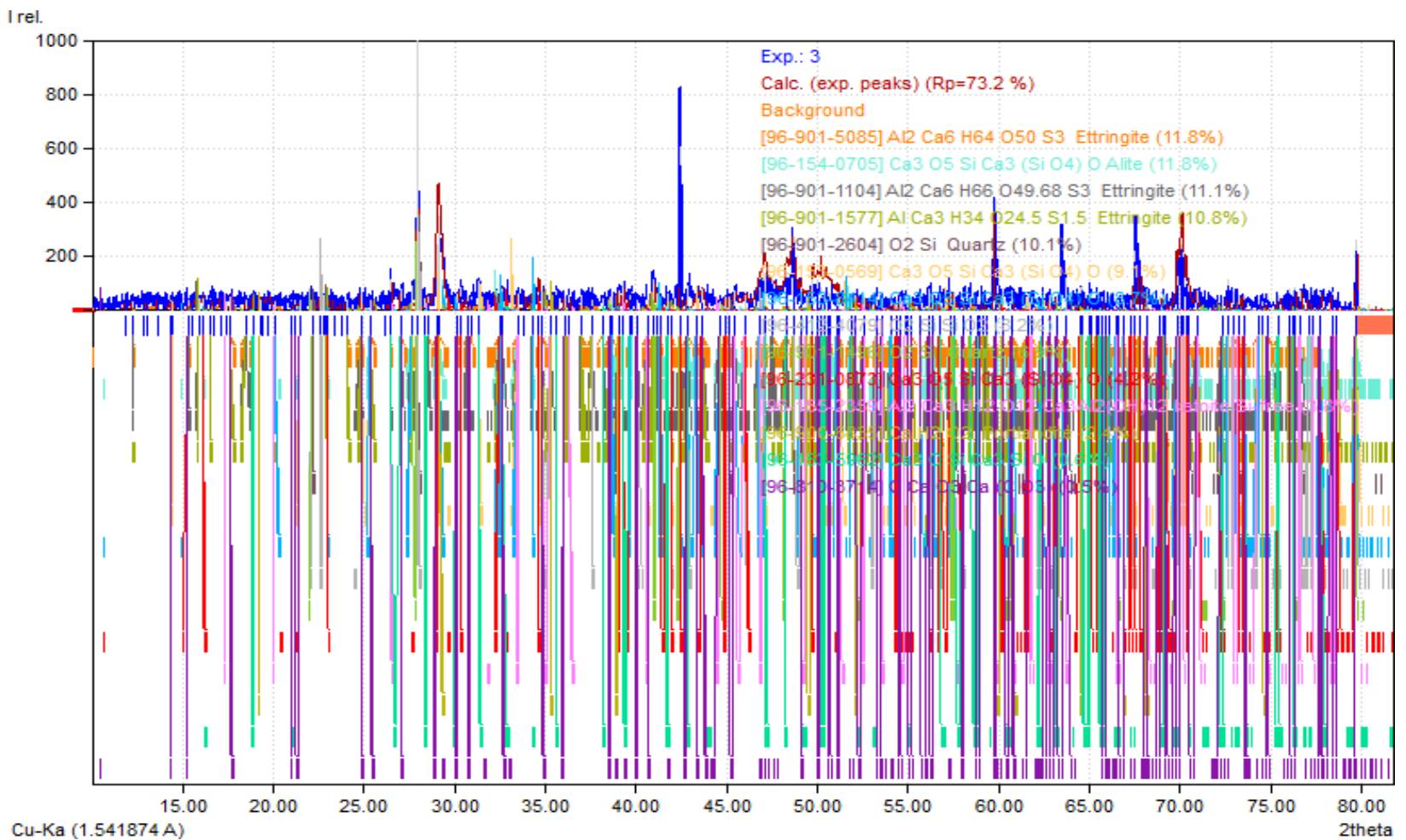

Figure. 35. Diffraction Pattern Graph of Cement Mortar Prepared with Treated Recycled Demolished Concrete Fine aggregate

\section{Field Adoptability Study}

The performance and functionality behavior of treated recycled demolished concrete coarse and fine aggregate are assessed in the laboratory under controlled conditions with reference to conventional aggregates. The field test and its adaptability in the field have to be assessed for its acceptance in the construction Industry. Therefore, the field adaptability and acceptance study are conducted by physically using the treated recycled demolished concrete aggregates using M30 grade for various civil related works, alongside the same grade of concrete prepared with conventional aggregates, and field tests such as nondestructive test are conducted to assess its performance 
in the field and the details of the same are discussed in detail.

a). In Road Construction Work (RC):- The two types of M 30 grade Concrete i.e., one made of conventional aggregates with plasticizers and the other made of treated recycled demolished concrete coarse and fine aggregate, are used for evaluation in road laying work at one of our sites. The thickness laid is $100 \mathrm{~mm}$, and the below figures show the same. It was observed that the finish and texture of both types of concrete are the same and both as per the field conditions cured for 14-days and on the cured concrete non-destructive tests as per IS code were performed. The results are tabulated graphically and from which we can infer that the field results are in full agreement with lab results and the rebound hammer value and core compressive strength value have shown an increase of $2 \%$ in treated recycled aggregate concrete as compared with that of the conventional concert.

b). In Plinth Protection Work (PC):- In technical terms, the area surrounding the building is usually known as the plinth protection. Plinth protection usually is done by pouring an approximate $100 \mathrm{~mm}$ layer of plain cement concrete along the edge of the building. The main idea behind this is to prevent water retention along the edge of the building, thus ensuring its long life. The above-prepared concrete as discussed in road work is used for plinth protection work and their performances are monitored and after 14-days of curing, the Non-destructive tests as per IS code were performed and the results are represented graphically in Figure 26, 27. Similar to the road construction work, the concrete prepared with treated aggregates has shown an increase of rebound value by $6.89 \%$ and core compressive strength by $8.42 \%$ as compared to concrete made of conventional aggregates.

c). In Storm Water Cover Preparation Work (SWDC):- Stormwater drain cover is used to cover the stormwater drains and to make it safe for people to walk on. Designed to give a good finish $\&$ high service life. In the present case 30nos of stormwater drain cover of size
$450 \mathrm{mmX} 600 \mathrm{~m}$ and thickness of $75 \mathrm{~m}$ are made using the angle supports at edges and with $8 \mathrm{~mm}$ dia reinforcement on either side. Out of 30Nos, 15 Nos are made by pouring concrete made of treated recycled demolished concrete coarse and fine aggregates and the remaining 15 Nos are made of conventional concrete using conventional aggregates. It was observed that the finish and texture of both types of concrete are the same and both as per the field conditions cured for 14-days and on the cured concrete non-destructive tests as per IS code were performed and the results are depicted graphically as shown below. Here, the concrete prepared with treated aggregates has also shown an increase of rebound value by $5.55 \%$ and core compressive strength by $8.76 \%$ as compared to concrete made of conventional aggregates.

d). Repair to Nonstructural Cracks (RPS):- The non-structural cracks occur mostly due to internally induced stresses in building materials and do not endanger the safety of a building but may look unsightly, or may create an impression of faulty work, or may give a feeling of instability. In some situations, due to penetration of moisture through them, non-structural cracks may spoil the internal finishes thus adding to the cost of maintenance, or corrode the reinforcement, thereby adversely affecting the stability of the structure in long run. One such Non Structural crack has been identified in one of our sites i.e. in one of our residential properties and the same was repaired by using plaster in some portions prepared with treated recycled fine aggregates and other portions with conventional plaster prepared with conventional aggregates. One such repair is done on the Concrete wall surface (RPCS) and the other on the Brick wall Surface (RPBS). Here, the mortar prepared with treated aggregates have also shown an increase of rebound value by $21.42 \%$ on the Concrete surface and 18.75 on the Brick wall surface and similarly, from the calibration curve the approximate compressive strength will be varied by $26.92 \%$ on the concrete wall surface and by $5.55 \%$ as compared to mortar made of conventional aggregates.

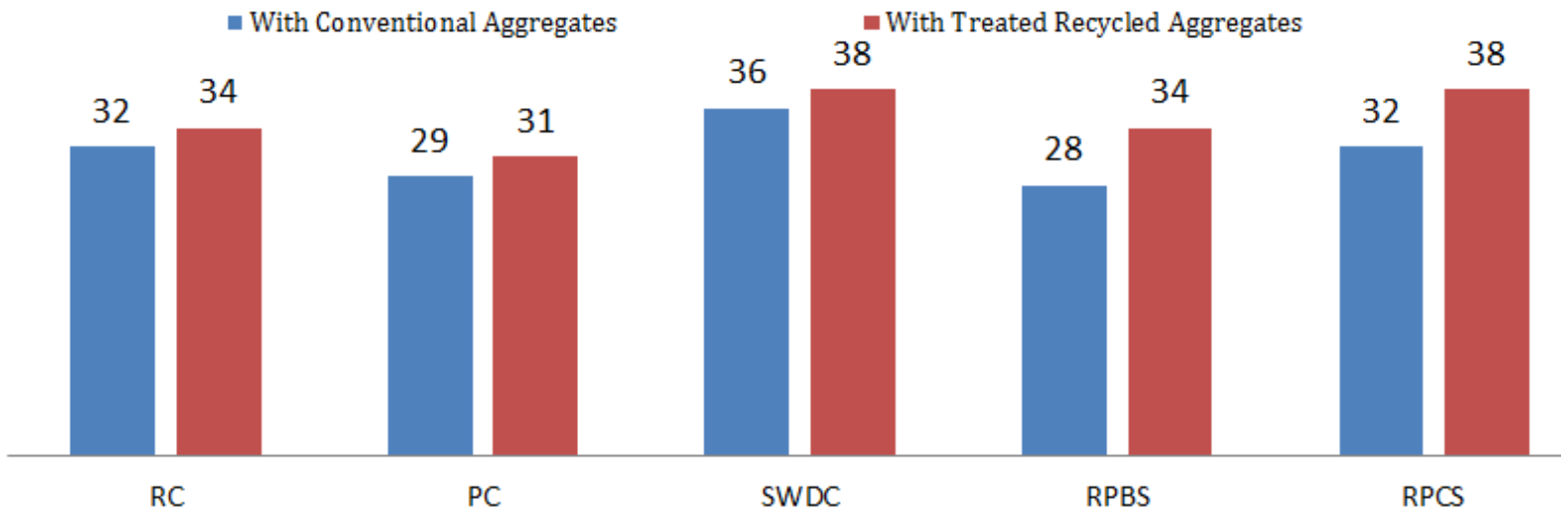

Figure 36. Rebound Hammer Test Values 


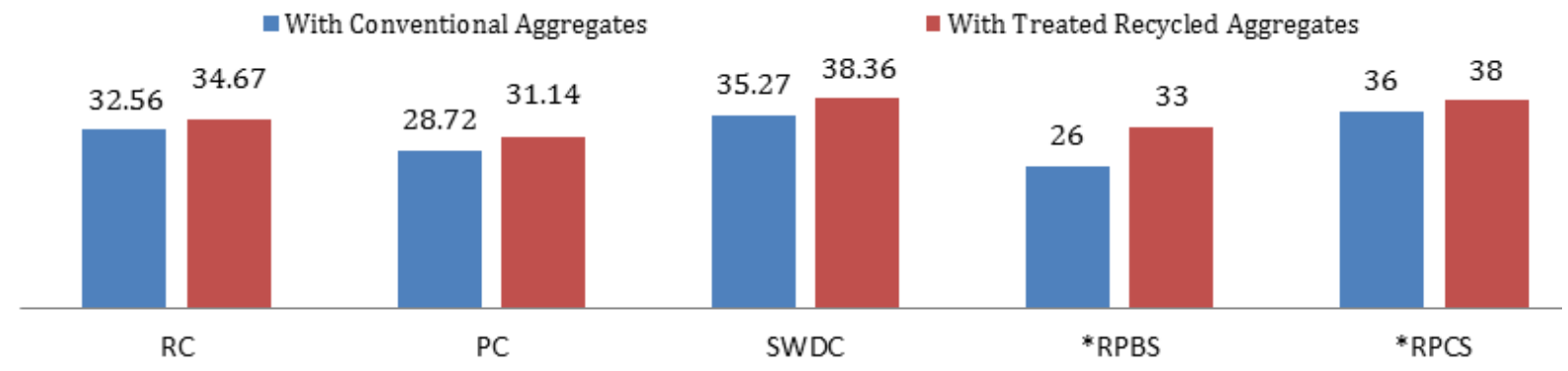

Figure 37. Test on Concrete Core Extract for Compressive Strength

*Average Compressive Strength (Mpa) From Calibration Curves

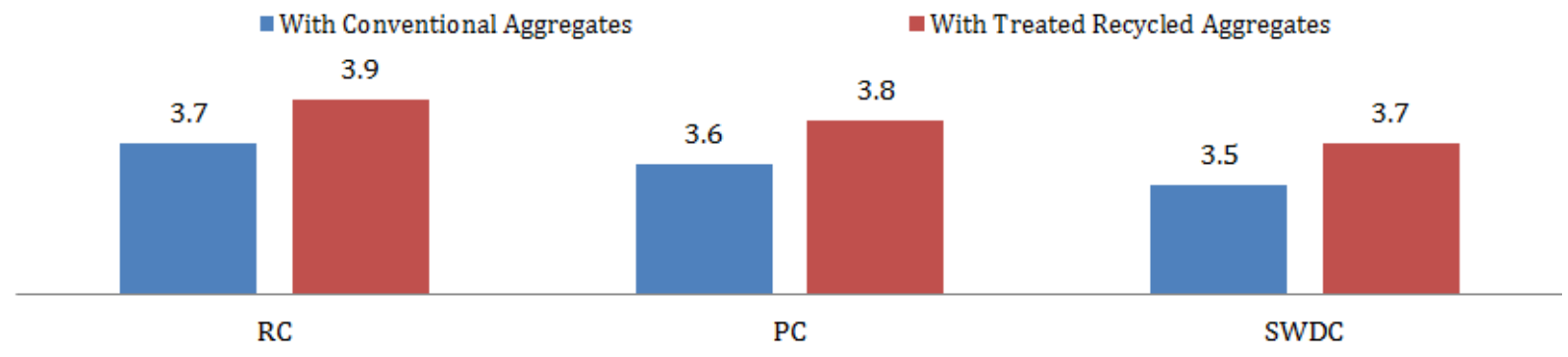

Figure 38. Ultrasonic Pulse Velocity Test Values

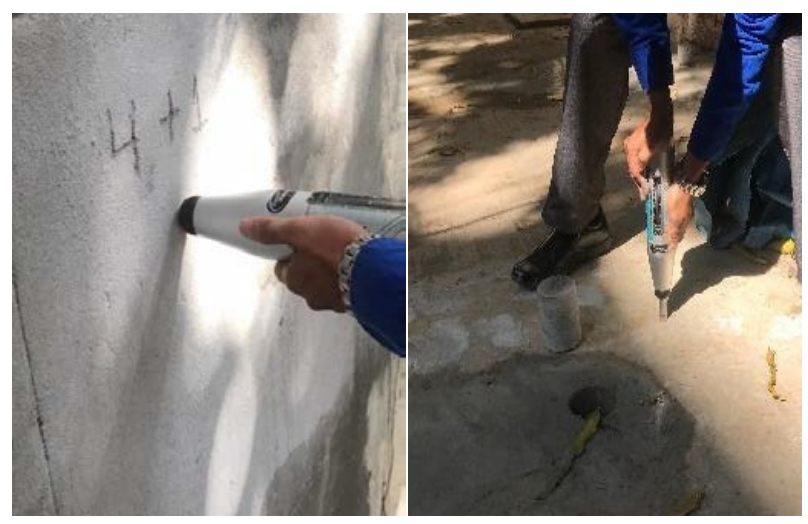

Figure 39. Rebound Hammer Test at Site

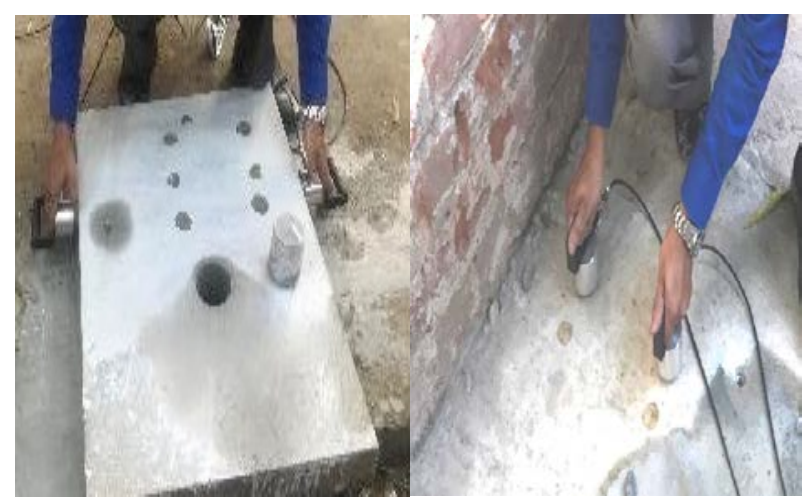

Figure 40. Ultrasonic Pulse Velocity Test At Site

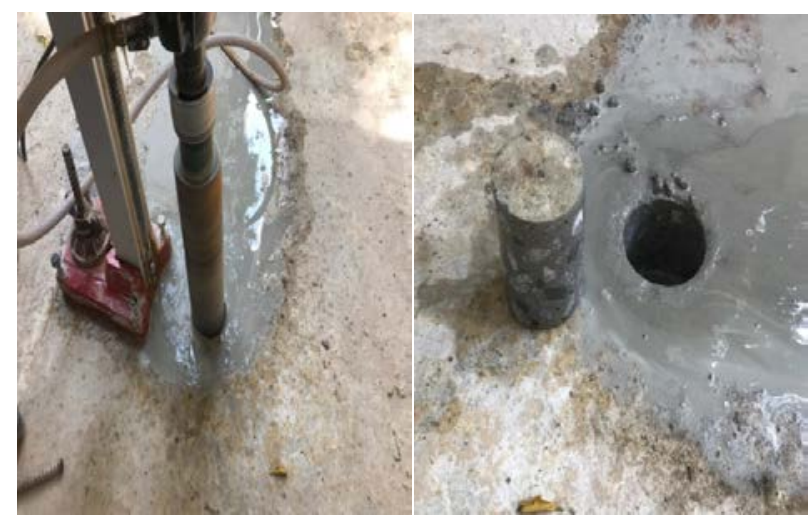

Figure 41. Core Cutting Apparatus' and Core Extraction at Site

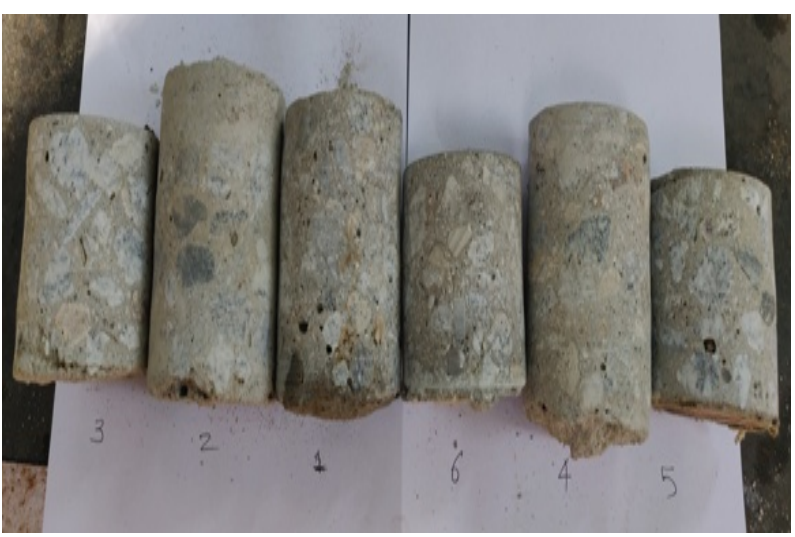

Figure 42. Different Types of Core Extracted at Site 


\section{Cost-Benefit Analysis (CBA)}

A CBA may be used to compare completed or potential courses of action, or to estimate (or evaluate) the value against the cost of a decision, project, or policy. The cost-benefit analysis was done on concrete and on cement mortar mass to access the cost of treatment technique and its usability in concrete construction as compared with that of cost of convention concrete/mortar mass at present used in the construction industry. The treatment method adopted proves to be $11.77 \%$ cheaper in concrete production as compared to conventional concrete and in cement mortar prepared with treated fine aggregates proves to be $33.33 \%$ cheaper as compared with mortar prepared with natural river sand.

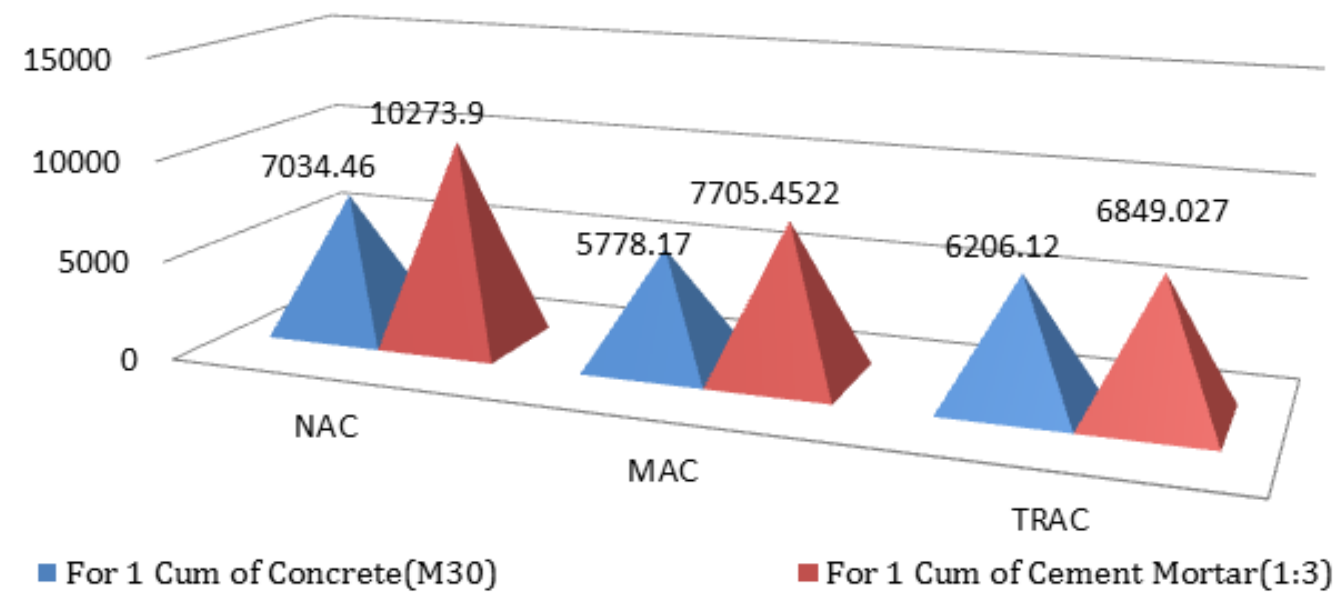

Figure 43. Cost Analysis Per Cum Of Concrete/Cement Mortar Production

\section{Discussion on Test Results}

From the obtained results, it was found that surface modification is the effective method of removing the surface defects and also the surface treatment method adopted has given the desire results in reducing the weakness the recycled aggregates in terms of reducing water absorption, improving the specific gravity and having strong interfacial zone, and based on theses a final combination of $2.5 \%$ of lithium silicate treatment on a recycled demolished concrete coarse aggregate and $1 \%$ colloidal silica dioxide treatment on demolished concrete fine aggregate found to be the best treatment for its usage in concrete and on the same combination the mechanical properties evaluated have shown that compressive strength has increased by $2.82 \%$, split tensile strength by $3.95 \%$, flexural strength by $20.83 \%$ and shear strength by $21.43 \%$ as compared to that of concrete made of conventional aggregates, further the concrete made of theses modified and treated aggregates has shown good resistance to fatigue loads by $3.67 \%$ and also to impact loads by $108.9 \%$ as against the conventional concrete. The durability test conducted on the concrete made of treated recycled aggregates has shown good resistance to acid by $5.11 \%$, sulphate attack by $6.28 \%$ and chloride attacks by $4.01 \%$ as compared to conventional concrete, further the impermeability test proves that treatment resulted in the strong impermeable surface which is around $44.3 \%$ more impermeable than conventional concrete, and as tested it produces an impermeable mass.

The microscopically study on the aggregates i.e, SEM images have shown that dense formation of the interfacial transition zone between the treated aggregates and the new mortar mass. From the shape of the chemical compound formed, it can be inferred that treatment resulted in more formation of Calcium Silicate and the formation seems to be more as compared with conventional concrete. The EDS data indicates the individual composition of chemical elements. From the obtained data, it can be inferred that treatment reduces the formation of internal lime i.e., the lime so generated from the hydration process has been used by the induced silicate in the formation of calcium silicate, thus strengthening the Calcium silicate hydrate family. The percentage of the association of silica with lime in treated aggregated is $67 \%$ as compared with the conventional concrete for which it is around $41 \%$. The same has been established below through the chemical equations. The XRD analysis has giving significant insight into the internal molecular structure, the spacing of molecular arrangement, and its behavioral aspects. The internal microscopic structural details have revealed how the molecular arrangement changed from one single arrangement to multiple structural arrangements i.e. from phase analysis report different samples under study obtained from XRD. Further, the analysis has shown how the increased percentage of crystallinity has a significant effect on reducing the crystal size and it helps in improving the distortions per unit volume. Thus, the macro analysis 
through SEM, EDS, and XRD helps us justify how the properties are enhanced by inducing the specified surface modification and treatment method and in what way it happened. The chemicals hydration reaction of cement with various types of aggregates can be defined as below.

\section{A. For Concrete/Mortar prepared with conventional aggregates}

When cement is added to the conventional aggregates along with water the following chemical reaction takes places

$$
\begin{aligned}
2\left(3 \mathrm{CaSiO}_{2}\right)+6 \mathrm{H}_{2} \mathrm{O} & =3 \mathrm{CaO} 2 \mathrm{SiO}_{2} 3 \mathrm{H}_{2} \mathrm{O}+3 \mathrm{Ca}(\mathrm{OH})_{2} \\
2\left(2 \mathrm{CaSiO}_{2}\right)+4 \mathrm{H}_{2} \mathrm{O} & =3 \mathrm{CaO} 2 \mathrm{SiO}_{2} 3 \mathrm{H}_{2} \mathrm{O}+\mathrm{Ca}(\mathrm{OH})_{2}
\end{aligned}
$$

It can be seen that Tricalcium Silicate produces a comparatively less quantity of calcium Silicate hydrates and more quantity of $\mathrm{Ca}(\mathrm{OH})_{2}$ than that formed in the hydration of Dicalcium Silicate. $\mathrm{Ca}(\mathrm{OH})_{2}$ is not the desired product in the concrete mass, it is soluble in water and gets leached out making the concrete porous. To the above problem, the treated aggregates will result in the nominal formation of any such type of lime, whereas the lime formation was severe in untreated Recycled Demolished Concrete aggregates

B. For concrete/Mortar prepared with recycled demolished concrete aggregates

When cement is added to the Treated Recycled Demolished Concrete aggregates along with water, the following chemical reaction takes places

$$
\begin{gathered}
2\left(3 \mathrm{CaSiO}_{2}\right)+\mathrm{xCa}(\mathrm{OH})_{2}+6 \mathrm{H}_{2} \mathrm{O}=3 \mathrm{CaO}_{2} \mathrm{SiO}_{2} 3 \mathrm{H}_{2} \mathrm{O}+(\mathrm{X}+3) \\
\mathrm{Ca}(\mathrm{OH})_{2} \\
2\left(2 \mathrm{CaSiO}_{2}\right)+\mathrm{xCa}(\mathrm{OH})_{2}+4 \mathrm{H}_{2} \mathrm{O}=3 \mathrm{CaO}_{2} \mathrm{SiO}_{2} 3 \mathrm{H}_{2} \mathrm{O}+(\mathrm{X}+1) \\
\mathrm{Ca}(\mathrm{OH})_{2}
\end{gathered}
$$

\section{For Concrete prepared with treated recycled demolished concrete aggregates}

When cement is added to the Treated Recycled Demolished Concrete aggregates along with water, the following chemical reaction takes places

$$
\begin{gathered}
2\left(3 \mathrm{CaSiO}_{2}\right) \mathrm{z}+\mathrm{x}\left(\mathrm{Li}_{2} \mathrm{SiO}_{3}\right)+\mathrm{y}\left(\mathrm{SiO}_{2}\right)+(\varnothing+\mathrm{z}) \mathrm{H}_{2} \mathrm{O}=6 \mathrm{CaO} \\
(\mathrm{x}+\mathrm{y}+2) \mathrm{SiO}_{2} \mathrm{zH}_{2} \mathrm{O}+\mathrm{Li}_{(\mathrm{x}+2)} \mathrm{O}_{(\varnothing+\mathrm{x})} \mathrm{H}_{(\varnothing+2)} \\
2\left(2 \mathrm{CaSiO}_{2}\right)+\mathrm{x}\left(\mathrm{Li}_{2} \mathrm{SiO}_{3}\right)+\mathrm{y}\left(\mathrm{SiO}_{2}\right)+(\varnothing+\mathrm{z}) \mathrm{H}_{2} \mathrm{O}=4 \mathrm{CaO} \\
(\mathrm{x}+\mathrm{y}+2) \mathrm{SiO}_{2} \mathrm{zH}_{2} \mathrm{O}+\mathrm{Li}_{(\mathrm{x}+2)} \mathrm{O}_{(\varnothing+\mathrm{x})} \mathrm{H}_{(\varnothing+2)}
\end{gathered}
$$

\section{For Mortar prepared with treated recycled demolished concrete aggregates}

When cement is added to the Treated Recycled Demolished Concrete aggregates along with water, the following chemical reaction takes places

$$
\begin{aligned}
& 2\left(3 \mathrm{CaSiO}_{2}\right)+\mathrm{x}\left(\mathrm{SiO}_{2}\right)+(\varnothing+\mathrm{y}) \mathrm{H}_{2} \mathrm{O}=6 \mathrm{CaO}(\mathrm{x}+2) \mathrm{SiO}_{2} \mathrm{yH}_{2} \mathrm{O} \\
& 2\left(2 \mathrm{CaSiO}_{2}\right)+\mathrm{x}\left(\mathrm{SiO}_{2}\right)+(\varnothing+\mathrm{y}) \mathrm{H}_{2} \mathrm{O}=4 \mathrm{CaO}(\mathrm{x}+2) \mathrm{SiO}_{2} \mathrm{yH}_{2} \mathrm{O}
\end{aligned}
$$

The surface treatment method adopted using the lithium silicates and Collidal silica controls the movement of hydroxide ions ( $\mathrm{OH}-)$ and makes them bonded with lithium. Thus, on overall restricting the movement of free hydroxide ions. Further, the free movement of $\mathrm{Ca}^{+}$is restricted as it reacts with silica dioxide and forms calcium silicate. Thus the treated aggregates not only redefined the hydration reaction but also modified the stress-strain curve, which encourages its usage in structural concrete works. Further, the field application and feasibility test have improved the concrete performance made of treated recycled aggregates. It has shown the superior performance of the treated recycled demolished concrete aggregates compared to that concrete made of conventional aggregates.

\section{Conclusions}

1. With a proper surface modification and surface treatment technique, it is possible to replace the complete natural aggregates in concrete with recycled demolished concrete aggregates for its usage in structural concrete works. The Ball mill method proves to be an effective method for removing the surface defects, brittle fractures, etc. on the surface of recycled demolished concrete coarse aggregates.

2. A combination of densification techniques on surface-modified recycled demolished concrete coarse and fine aggregate resulted in improvement of aggregate properties which are of improved nature as compared with that of properties of natural aggregates. Recycled demolished concrete fine aggregate treated with $1 \%$ colloidal silica dioxide can be used as a complete replacement material for sand in cement mortar and concrete. Similarly, recycled demolished concrete coarse aggregate treated with $2.5 \%$ lithium silicate can be used as a complete replacement material for natural coarse aggregate in concrete. The strength and durability parameters tested with the above-treated aggregates are much higher than for concrete specimens prepared with conventional coarse and fine aggregates.

3.Concrete made of treated recycled demolished concrete coarse and fine aggregates has high compressive strength by $2.82 \%$, split tensile strength by $3.95 \%$, flexural strength by $20.8 \%$, Impact strength by $3.67 \%$, and shear strength by $21.42 \%$, as compared with that of concrete made of natural coarse and fine aggregates. Similarly, the stress-strain analysis proves the concrete with TRCA is more elastic by $3.67 \%$ and more ductile by $7.57 \%$ (i.e. area covered is more in stress-strain cure by treated recycled aggregates), as compared with that of conventional concrete.

4. At 180 days, the concrete made of treated recycled demolished concrete coarse and fine aggregates fared well compared with that of untreated recycled aggregates and has superior performance in all serviceability parameters 
i.e., under acid attack the resistance is up to $5.4 \%$, under sulfate attack, it was about $6.28 \%$ and under the chloride attack it is about $4 \%$, as compared with that of conventional concrete.

5. From the permeability and water absorption data of concrete prepared with treated aggregates indicated the \% of reduction of pores by $45 \%$ and it has improved resistance to water by $17 \%$ as compared with that of conventional concrete. The treated recycled demolished concrete aggregates resulted in dense mass with minimal interconnected voids

6. From SEM data, it can be inferred that concrete and cement mortar prepared with the treated recycled demolished concrete aggregates has a dense packing and minimal interfacial transition zone, this makes the concrete/mortar mass of superior quality and better in performance. "From the structure of the compounds, it can be inferred that treated recycled demolished concrete aggregates usage has resulted in more formation of calcium silicate hydrate compounds and minimal generation of calcium hydroxides”.

7.The EDS data on treated aggregates resulted in the formation of low $\mathrm{Ca} / \mathrm{Si}$ ratio than that of untreated aggregates, it can be interpreted that the silica content associated with calcium in conventional aggregate is around $41.20 \%$ and with untreated aggregates, treated aggregates it is around $21.01 \%$ and $67.61 \%$, which indicates the more formation of calcium silicate in the concrete prepared with treated recycled demolished concrete aggregates as compared with that of conventional concrete and with that of untreated recycled demolished concrete aggregates

8. From XRD data, the following can be inferred,

a). The densification of recycled demolished concrete aggregates has resulted in more calcium silicate hydrate formation (to the tune of $39.5 \%$ ) on the adhered mortar surface which contributed to filling the pores and formation of dense mass on the surface and concrete of the aggregates prepared with these densified aggregates which in turn resulted in more percentage formation of calcium silicate hydrates, ettringite. The usage intern resulted in the formation of a strong interfacial transition zone between the internal components of the concrete to the extent of $26.82 \%$ as compared to conventional concrete. The case is similar in using treated recycled demolished concrete fine aggregates in Cement Mortar where the improvement is by $8.9 \%$ as compared with conventional mortar.

b). The detailed microanalysis on the concrete and mortar mass indicates the multimolecular structural arrangement in concrete mass prepared with treated aggregates; this arrangement ensures the dense arrangement of molecules which can be inferred by the least spacing of molecular planes ( by 32.95\%) and with a minimal size of the crystal lattice ( by
28.11\%) and more \% of crystalline( by 9\%). The above behavior is quite reverse in concrete/mortar mass prepared with conventional and untreated aggregates.

c). Further the distortional density and Microstrain is more for concrete mass prepared with Conventional aggregates when compared with that of concrete mass prepared with treated recycled aggregates, which indicates the least presence of dislocation numbers and surface restructuring in concrete mass prepared with treated recycled demolished concrete aggregate.

9. From the field adaptability study, the surface-modified and surface treated recycled demolished concrete aggregates are easily adaptable to site conditions for any type of work. Infield usage the concrete prepared with treated aggregates have shown an increase in compressive strength by $4.23 \%$ (average) and an improvement in rebound hammer value by $5.5 \%$ (average) as compared to that of conventional concrete. Similarly, usages of treated fine aggregates in cement mortar have improved the rebound value by $21 \%$ (average) as compared to that of conventional cement mortar.

10. From the cost-benefit analysis, it can be inferred that using treated recycled demolished concrete aggregates; standard-grade concrete can be achieved at a $12 \%$ smaller amount compared to that of conventional concrete, without compromising on strength and durability parameters. This helps us in the production of low-cost, eco-friendly green concrete.

\section{REFERENCES}

[1] IS 4031-1968, Indian Standard, METHOD OF PHYSICAL TESTS FOR HYDRAULIC CEMENT, Bureau of Indian Standards.

[2] Amnon Katz, "Treatment methods to be adopted for the improvement of recycled aggregate”, Journal of Materials in Civil Engineering, ASCE, Vol.16, No.6, pp.597-603, December 1, 2004, DOI: 10.1061(ASCE)0899-1561(2004)16:6(597).

[3] IS 2116-1980, Indian Standard, SPECIFICATION FOR SAND FOR MASONRY MORTARS (first revision).

[4] Wolfgang Kunther, Segio Ferreiro and Jorgen Skidsted, "Influence of the $\mathrm{Ca} / \mathrm{Si}$ ratio on the compressive strength of cementitious calcium-silicate-hydrate binders”, Journal of Material Chemistry A 2017.5, pp .17401-17412, July 26-2017, DOI:10.1039/c7ta06104h.

[5] Shashi B.Atla, Yi-Hsun Huang, James Yang, How-Ji Chen, Yi-Hao Kuo, Chun-Mei Hsu, Wen-Chien Lee, Chien-Cheng Chen, Duen-Wei Hsu and Chien-Yen Chen -Hydrophobic Calcium Carbonate for Cement Surface-Crystal journal, MDPI,7, 371, pp .2-9, DOI:10.3390/cryst7120371.

[6] Hwa -Sung Ryu, Deuck Mo Kim, Sang- Heon Shin, Seung Minlim \& Wan - Jun park,” Evaluation on the Surface 
Modification of Recycled aggregate in aqueous H2SiF6 solution”, International Journal of Concrete Structures and Materials 2018 12-19.DOI: 10.1186/s40069-018-02565-5.

[7] W.Y. Tam, Vivian, Gao, X., Tam, C- "Microstructural analysis of recycled aggregate concrete produced from two-stage mixing approach”, Cement and Concrete Research 2005, Volume 35, Issue 6, June 2005, Pages 1195-1203, https://doi .org /10.1016/j.cemconr es.2004.10.025.

[8] Hasbi Yaprak1, Huseyin Y1lmaz Aruntas2, Ilhami Demir3, Osman Simsek2, and Gokhan Durmus- "Effects of the fine recycled concrete aggregates on the concrete properties"International Journal of the Physical Sciences Vol. 6(10), pp. 2455-2461, 18 May 2011, DOI: 10.5897/IJPS11.253.

[9] Stefan Baueregger, Margarita Perello, Johann Plank, "Influence of anti-caking agent kaolin on film formation of ethylene-vinyl acetate and carboxylated styrene-butadiene latex polymers”, Cement and Concrete Research, Volume 58, pp. 112-120, April 2014, DOI: 10.1016/j.cemconres.2014.01.017.

[10] Ramtin Movassaghi, "Durability of Reinforced Concrete Incorporating Recycled Concrete as Aggregate (RCA)”, A thesis presented to the University of Waterloo towards Fulfillment of Master of Applied Science-2006, Waterloo, Ontario, Canada, 2006.

[11] Aastha, Dr. R. R. Singh "Effect of Recycled Aggregates on the Mechanical Properties of Concrete- by - International Research Journal of Engineering and Technology, Volume: 05, Issue 10, pp.33-35, Oct 2018, e-ISSN: 2395-0056/p-ISSN: 2395-0072.

[12] Valerie Spaeth, Assia Djerbi Tegguer "Improvement of recycled concrete aggregate properties by polymer treatments”, International Journal of Sustainable Built Environment (2013)2, pp.143-152, March 23, 2014, DOI:10.1016/j.ijsbe.2014.03.003.

[13] Zengfeng Zhao, Sebastien Remond, Denis Damidot, Weiya $\mathrm{Xu}$, "Influence of fine recycled concrete aggregates on the properties of mortars", Construction and Building Materials 81(2015), pp. 179-186, February 18, 2015. DOI:10.1016/j.conbuildmat.2015.02.037.

[14] O.O.Adefisan, J.S.Fabiyi, and A.G.Mc Donald,” Hydration Behaviour and Infrared Spectroscopy of Pre-treatments Effect on Portland Cement -Eremospatha Macrocarpa and Laccosperma Secundiflorum System”, Journal of Applied Sciences 12(3), pp 254-262, 2012, DOI: 10.3923/jas.2012.254.262.

[15] Cheng-Chih Fan, Ran Huang, Howard Hwang, and Sao-Jeng Chao," The Effect of Different Fine Recycled Concrete Aggregates on the Properties of Mortar”, Materials Journal, MDPI, Volume.8, pp.2658-2672, May16-2015, DOI: 10.3390/ma8052658. 